\title{
Terameprocol, a methylated derivative of nordihydroguaiaretic acid, inhibits production of prostaglandins and several key inflammatory cytokines and chemokines
}

\author{
D Eads, RL Hansen, AO Oyegunwa, CE Cecil, CA Culver, F Scholle, ITD Petty \\ and SM Laster*
}

Address: Department of Microbiology, North Carolina State University, Raleigh, NC 27695, USA

Email: D Eads - dawn_eads@ncsu.edu; RL Hansen - rebecca_hansen@ncsu.edu; AO Oyegunwa - bola.oyegunwa@gmail.com; CE Cecil - chad_cecil@ncsu.edu; CA Culver - cariculver@yahoo.com; F Scholle - frank_scholle@ncsu.edu; ITD Petty - tim_petty@ncsu.edu; SM Laster* - scott_laster@ncsu.edu

* Corresponding author

Published: 8 January 2009

Received: 30 July 2008

Journal of Inflammation 2009, 6:2 doi:10.1 186/1476-9255-6-2

Accepted: 8 January 2009

This article is available from: http://www.journal-inflammation.com/content/6/I/2

(c) 2009 Eads et al; licensee BioMed Central Ltd.

This is an Open Access article distributed under the terms of the Creative Commons Attribution License (http://creativecommons.org/licenses/by/2.0), which permits unrestricted use, distribution, and reproduction in any medium, provided the original work is properly cited.

\begin{abstract}
Background: Extracts of the creosote bush, Larrea tridentata, have been used for centuries by natives of western American and Mexican deserts to treat a variety of infectious diseases and inflammatory disorders. The beneficial activity of this plant has been linked to the compound nordihydroguaiaretic acid (NDGA) and its various substituted derivatives. Recently, tetra-Omethyl NDGA or terameprocol (TMP) has been shown to inhibit the growth of certain tumorderived cell lines and is now in clinical trials for the treatment of human cancer. In this report, we ask whether TMP also displays anti-inflammatory activity. TMP was tested for its ability to inhibit the LPS-induced production of inflammatory lipids and cytokines in vitro. We also examined the effects of TMP on production of TNF- $\alpha$ in C57BL6/J mice following a sublethal challenge with LPS. Finally, we examined the molecular mechanisms underlying the effects we observed.
\end{abstract}

Methods: RAW 264.7 cells and resident peritoneal macrophages from C57BL6/J mice, stimulated with I $\mu \mathrm{g} / \mathrm{ml}$ LPS, were used in experiments designed to measure the effects of TMP on the production of prostaglandins, cytokines and chemokines. Prostaglandin production was determined by ELISA. Cytokine and chemokine production were determined by antibody array and ELISA.

Western blots, q-RT-PCR, and enzyme assays were used to assess the effects of TMP on expression and activity of COX-2.

q-RT-PCR was used to assess the effects of TMP on levels of cytokine and chemokine mRNA.

C57BL6/J mice injected i.p. with LPS were used in experiments designed to measure the effects of TMP in vivo. Serum levels of TNF- $\alpha$ were determined by ELISA.

Results: TMP strongly inhibited the production of prostaglandins from RAW 264.7 cells and normal peritoneal macrophages. This effect correlated with a TMP-dependent reduction in levels of COX-2 mRNA and protein, and inhibition of the enzymatic activity of COX-2.

TMP inhibited, to varying degrees, the production of several cytokines, and chemokines from RAW 264.7 macrophages and normal peritoneal macrophages. Affected molecules included TNF- $\alpha$ and 
MCP-I. Levels of cytokine mRNA were affected similarly, suggesting that TMP is acting to prevent gene expression.

TMP partially blocked the production of TNF- $\alpha$ and MCP-I in vivo in the serum of C57BL6/J mice that were challenged i.p. with LPS.

Conclusion: TMP inhibited the LPS-induced production of lipid mediators and several key inflammatory cytokines and chemokines, both in vitro and in vivo, raising the possibility that TMP might be useful as a treatment for a variety of inflammatory disorders.

\section{Background}

The creosote bush, Larrea tridentata, is common in the Sonoran deserts of Mexico and the American southwest. The Pima, Yaqui, Maricopa and Seri tribes have used various extracts and preparations from this plant to treat a wide variety of disorders $[1,2]$. The leaves can be used in a bath for chicken pox or rheumatism, while a decoction made from the boiled leaves is used as a poultice for skin sores. Skin sores can also be treated with a powder made from dried leaves and stems. The leaves can be used to make a tea (chaparral tea) that is used to treat many disorders including cancer, venereal disease, tuberculosis, colds, and rheumatism. Consumption of high levels of $L$. tridentata can cause hepatic necrosis [3,4], although damage is temporary and reversed when $L$. tridentata is withdrawn from the diet.

The leaves and stems of L. tridentata contain high quantities of the phenolic compound nordihydroguaiaretic acid (NDGA), a lipophilic anti-oxidant that has been used as a preservative in fats and oils. Many of the medicinal effects of $L$. tridentata have also been attributed to the effects of this compound [2]. NDGA has been shown to inhibit 5lipoxygenase activity in vitro $[5,6]$, and experiments have shown that it inhibits neutrophil production of $\mathrm{LTB}_{4}$ $[7,8]$, degranulation $[7,8]$, phagocytosis [9], and the respiratory burst [9]. NDGA affects levels of intracellular calcium $[10,11]$, as well as exerting effects on mitochondria $[12,13]$, and the Golgi complex [14-16]. NDGA has been shown to exert anti-tumor effects [17] and to block apoptosis induced either by tumor necrosis factor- $\alpha$ (TNF) [1821] or CD95 ligand [22,23].

L. tridentata leaves also contain 3-O-methyl NDGA, with one methyoxl and three hydroxyl side chains rather than the four hydroxyl groups found on NDGA [24]. 3-Omethyl NDGA has been shown to inhibit replication of a number of strains of HIV and prevent both basal transcription and Tat-regulated transactivation in vitro [24]. This effect arises from the ability of 3-O-methyl NDGA to interfere with the binding of the transcription factor Sp1 to the long terminal repeats of HIV, an effect that was not seen with NDGA itself [24]. Based on these results, eight distinct methylated forms of NDGA were tested for their effects on HIV Tat-mediated transactivation [25]. The results of this investigation revealed that tetra-O-methyl NDGA (also known as M4N or terameprocol (TMP)) displayed the highest level of anti-HIV activity [25]. TMP has also been shown to block the replication of herpes simplex virus in vitro [26] and to inhibit transcription from the early promoter $\mathrm{P}_{97}$ of human papillomavirus 16 in transfected cells [27]. Both effects were again attributed to the ability of TMP to interfere with the binding of Sp1 to DNA. TMP has been found to arrest the growth of certain tumor-derived cell lines in the $G_{2}$ phase of the cell cycle by inhibiting production of cyclin-dependent kinase cdc2 mRNA [28]. Experiments in vivo with mice, with a number of different tumor-derived and transformed cell lines, revealed a similar growth inhibitory effect resulting from decreased gene expression of both cdc2 and survivin $[28,29]$ leading to the suggestion that TMP may be useful in humans to treat cancer. Indeed, three clinical trials with TMP to treat human tumors have been completed and two more are now underway (Clinicaltrials.gov database, accessed 5/28/08).

In this report we have investigated a novel role for TMP; as an inhibitor of inflammation. We reasoned that TMP might have anti-inflammatory activity since many of the disorders for which L tridentata is traditionally used contain an inflammatory component. In this manuscript we have focused on TMP's ability to inhibit production of inflammatory lipids and cytokines from macrophages and macrophage-like cells. The results of our experiments reveal inhibition of both cytokine and lipid mediator production and suggest that multiple molecular mechanisms underlie these effects. Overall, our data suggest that TMP may be useful in clinical situations to treat a variety of inflammatory disorders.

\section{Methods \\ Cells and Media}

RAW 264.7 cells were obtained from the American Type Culture Collection (Manassas, VA) and were cultured in Dulbecco's Modified Eagle's (DME) Medium with $4 \mathrm{mM}$ L-glutamine, $4.5 \mathrm{~g} / \mathrm{L}$ glucose, $1.5 \mathrm{~g} / \mathrm{L}$ sodium bicarbonate with $10 \%$ FCS. Most media and supplements were obtained from Sigma-Aldrich, St. Louis, MO. FCS was 
obtained from Atlanta Biologicals, Atlanta, GA. For production of cell culture supernatants, $1.5 \times 10^{5}$ cells/well were plated in 24 well tissue culture plates in $1 \mathrm{ml}$ culture media. Following treatment, supernatants were collected, centrifuged for $2 \mathrm{~min}$ at $8,000 \mathrm{rpm}$ to remove debris, aliquoted and stored at $-80^{\circ} \mathrm{C}$. Normal resident peritoneal macrophages were obtained from 8-10 week old C57BL6/J mice (Charles River Laboratories, Inc. Wilmington, MA). Peritoneal lavage was performed with DME serum-free media. Following washing, the resulting cells were plated in DME with 10\% FCS, incubated overnight, and then washed to remove non-adherent cells.

\section{Chemicals and Biological Reagents}

Unless otherwise indicated, reagents were purchased from Sigma-Aldrich, St. Louis, MO. TMP was supplied by Erimos Pharmaceuticals, Raleigh, NC. DMSO was used as the solvent for TMP in all experiments except for those performed in vivo with mice. The maximum DMSO concentration was $1.0 \%$ in all assays. This concentration of DMSO was tested in all assays and did not affect the results. LPS from Salmonella Minnesota R595 was purchased from LIST Biological Laboratories, Inc. (Campbell, CA).

\section{ELISA kits}

PGE $_{2}$, 6-keto-PGF ${ }_{1 \alpha}$, MCP-1, IL-12/23 p40, RANTES, and TNF- $\alpha$ ELISA kits were purchased from R\&D Systems (Minneapolis MN), Assay Designs (Ann Arbor, MI), eBioscience (San Diego, CA), or USBiological (Swampscott, $\mathrm{MA})$. The $\mathrm{PGF}_{2 \alpha}$ kit was purchased from Assay Designs and the IL-23p19 kit was purchased from eBioscience. All lipid mediator kits are competitive type immunoassays while the cytokine kits are direct capture assays. In each case, sample values were interpolated from standard curves. Optical density was determined using a PolarStar microplate reader (BMG Labtechnologies, Durham, NC).

\section{Cytokine arrays}

For cytokine analysis, the RayBio Mouse Inflammation Antibody Array I was purchased from RayBiotech, Inc., Norcross, GA. According to manufacturer's instructions, the array membranes were incubated with blocking buffer followed by undiluted culture supernatants for $1.5 \mathrm{~h}$. Then, the membranes were washed, incubated with biotin-conjugated Abs for $1.5 \mathrm{~h}$ and HRP-conjugated strepavidin for $2 \mathrm{~h}$. The membranes were next incubated in detection buffer and exposed to X-ray film. Finally, scans of the X-ray films were analyzed with Photoshop (Adobe) to determine spot density.

\section{Intraperitoneal challenge with LPS}

Animal experiments were carried out in accord with approved IACUC protocol. Each group of experimental animals consisted of 5, 6-8 week old, 15-16 g C57BL6/J mice (Charles River). The groups received i.p. injections of either PBS, hydroxypropyl- $\beta$-cyclodextrin with PEG 300 (CPE) vehicle [30], $20 \mu \mathrm{g}$ of LPS in CPE vehicle, $1 \mathrm{mg}$ of TMP in CPE vehicle, or $20 \mu \mathrm{g}$ of LPS and $1 \mathrm{mg}$ TMP in vehicle. CPE vehicle and TMP/CPE vehicle injections were administered $1 \mathrm{~h}$ prior to LPS or PBS injections. Injection volumes were $100 \mu \mathrm{l}$ for TMP and vehicle and $200 \mu \mathrm{l}$ for LPS and PBS. The mice were monitored for 3 hours, sacrificed, and blood collected by cardiac puncture. Serum was separated and levels of TNF- $\alpha, \mathrm{PGE}_{2}$, and MCP-1 determined by ELISA.

\section{Collection of peritoneal macrophages}

Macrophages were collected by peritoneal lavage from 68 week old C57BL6/J mice (Charles River).

After collection the cells were centrifuged, counted and plated at $2 \times 10^{5}$ per well in 24 well tissue culture plates. The cells were allowed to adhere for 2-4 hr, washed to remove non-adherent cells and then treated as described within $24 \mathrm{~h}$.

\section{Quantitative RT-PCR assays}

Total RNA of treated and untreated cells was extracted using the RNAeasy kit (Qiagen, Valencia, CA) according to manufacturer's specifications. Residual genomic DNA was eliminated by using on-column DNase digestion with the RNase-free DNase set (Qiagen) and resulting extracts were resuspended in nuclease free water. Total amount and purity of RNA was determined using a Nanodrop 1000 spectrophotometer (ThermoFisher Scientific, Waltham, MA). Total RNA ( $1 \mu \mathrm{g})$ was denatured and reverse transcription was performed with the Improm ll reverse transcription kit (Promega, Madison, WI) in a reaction mix containing random hexamers as primers $(50 \mathrm{ng} / \mu \mathrm{l})$ for 60 $\min$ at $42^{\circ} \mathrm{C}$. The iQTM SYBR Green supermix kit (BioRad, Hercules, CA), was used for Real-time PCR analysis, cDNA was amplified using primers specific for murine GAPDH, TNF- $\alpha$, MCP-1, RANTES and COX-2. Primer combinations are GAPDH [antisense: 5' ATG TCA GAT CCA CAA CGG ATA GAT 3'; sense: 5' ACT CCC TCA AGA TTG TCA GCA AT 3']; TNF- $\alpha$ [antisense: 5' AGA AGA GGC ACT CCC CCA AAA 3'; sense: 5' CCG AAG TTC AGT AGA CAG AAG AGC G 3']; MCP-1 [sense: 5' CAC TAT GCA GGT CTC TGT CAC G 3'; antisense: 5' GAT CTC ACT TGG TTC TGG TCC A 3']; RANTES: [sense: 5' CCC CAT ATG GCT CGG ACA CCA 3'; antisense: 5' CTA GCT CAT CTC CAA ATA GTT GAT 3']; COX-2: [sense: 5' GCA TTC TTT GCC CAG CAC TT 3'; antisense: 5' AGA CCA GGC ACC AGA CCA AAG A 3']. All primer pairs were purchased from Integrated DNA Technologies, Coralville, IA. Cycling conditions for all PCRs are available upon request.

PCR was performed in 96 well plates (Eppendorf AG, Hamburg, Germany). Samples were amplified for a total of 50 cycles, followed by a meltcurve analysis to ensure 
the specificity of reactions. To generate a standard curve, total RNA was isolated from the cells and 300-600 bp fragments of the gene of interest were amplified by RTPCR using cognate primer sets. PCR fragments were gel purified, quantified and the copy number was calculated. Serial ten fold dilutions were prepared for use as templates to generate standard curves. All samples were normalized to amplified murine GAPDH. GAPDH control was analyzed per plate of experimental genes to avoid plate-toplate variation. Final RT-PCR data is expressed as the ratio of copy numbers of experimental gene per $10^{3}$ copies of GAPDH for samples performed in duplicates.

\section{Peroxidase Assay for the measurement of COX-2 Activity} Inhibition of the peroxidase activity of purified COX-2 enzyme was measured using a modified chromogenic assay, described previously [31], in which $\mathrm{N}, \mathrm{N}, \mathrm{N}^{\prime}, \mathrm{N}^{\prime}$ tetramethyl-p-phenylenediamine (TMPD) was utilized to measure the oxidation of $\mathrm{PGG}_{2}$ to $\mathrm{PGH}_{2}$. Briefly, approximately $100 \mathrm{U} / \mathrm{ml}$ of ovine COX-2 (Cayman Chemical Co., Ann Arbor, MI) was mixed with an assay buffer containing $100 \mathrm{mM}$ Tris- $\mathrm{HCl} \mathrm{pH}$ 8.0, $1 \mu \mathrm{M}$ bovine hemin and the inhibitor TMP. This mixture was incubated in a temperature controlled $1 \mathrm{~cm}$ glass cuvette at $25^{\circ} \mathrm{C}$ for 10 minutes to allow for enzyme and inhibitor equilibration. The peroxidase activity of the COX-2 enzyme was initiated by adding $100 \mu \mathrm{M}$ arachidonic acid. TMPD $(170 \mu \mathrm{M}$ final $)$ was added at the same time as the arachidonic acid and the reaction was monitored for six minutes using a Shimadzu UV-2401PC kinetic reading spectrophotometer (Shimadzu, Kyoto, Japan) at $611 \mathrm{~nm}$. Absorbance was recorded at one second intervals using UV probe software (Shimadzu). After three minutes hydrogen peroxide was added to a final concentration of $70 \mu \mathrm{M}$ to further catalyze the peroxidase reaction and the kinetic reading was continued for an additional three minutes. Control reactions were analyzed without inhibitor or without enzyme for comparison.

\section{Immunoblotting}

Cell monolayers were washed twice with cold phosphate buffered saline (PBS), solubilized in lysis buffer $(50 \mathrm{mM}$ Hepes, pH 7.4, 1 mM EGTA, 1 mM EDTA, 0.2 mM sodium orthovanadate, $1 \mathrm{mM}$ phenylmethylsulfonyl fluoride, 0.2 $\mathrm{mM}$ leupeptin, $0.5 \% \mathrm{SDS}$ ), and collected by scraping. The protein concentration for each sample lysate was determined using the Pierce BCA system (Pierce, Rockford, IL). Equal protein samples (15 to $30 \mu \mathrm{g}$ ) were loaded on $8 \%$ Tris-Glycine gels and subjected to electrophoresis using the Novex Mini-Cell System (Invitrogen). Following transfer, blocking and probing, bands were visualized using the SuperSignal Chemiluminescent system (Pierce, Rockford, IL). Scans of films were then analyzed with Photoshop (Adobe) to determine band density.

\section{[ $\left.{ }^{3} \mathrm{H}\right] \mathrm{AA}$-release assays}

$2.5 \times 10^{4}$ cells were plated into 24-well flat-bottom tissue culture plates (Fisher Scientific, Pittsburgh, PA) and labeled overnight with $0.1 \mu \mathrm{Ci} / \mathrm{ml}\left[{ }^{3} \mathrm{H}\right] \mathrm{AA}$. The following morning, the cells were washed $2 \times$ with Hank's balanced salt solution (HBSS), allowed to recover for an additional $2 \mathrm{~h}$, and washed again prior to treatment. At indicated time points, $275 \mu \mathrm{l}$ aliquots of media were removed from the wells and centrifuged to remove debris. $200 \mu \mathrm{l}$ of the supernatant was removed for scintillation counting (LS 5801, Beckman, Fullerton, CA) and total [ $\left.{ }^{3} \mathrm{H}\right] \mathrm{AA}-$ release was calculated by multiplying by a factor of 2 . Each point was performed in triplicate and maximum radiolabel incorporation was determined by lysing untreated controls with $0.01 \%$ SDS and counting the total volume.

\section{Influenza A virus propagation}

Influenza A/PR/8/34 (VR-1469) was purchased from the American Type Culture Collection (Manassas, VI) and propagated in MDCK Cells (ATCC CCL-34). T-75 flasks of cells at $90 \%$ confluency were inoculated with $0.01 \mathrm{MOI}$ of virus in $2 \mathrm{ml}$ of Virus Growth Medium (VGM) made up of DMEM containing 0.2\% BSA, $25 \mathrm{mM}$ Hepes buffer, 100 $\mathrm{U} / \mathrm{ml}$ Penicillin, $100 \mu \mathrm{g} / \mathrm{ml}$ Streptomycin, and $2 \mu \mathrm{g} / \mathrm{ml}$ TPCK-treated Trypsin (LS003740, Worthington-Biochem, Lakewood, NJ). Viral supernatants were harvested at 36 to $48 \mathrm{~h}$, centrifuged to remove cellular debris, and supplemented with BSA to a final concentration of $0.5 \%$. Aliquots were frozen and stored at $-80^{\circ} \mathrm{C}$. Titers of influenza A virus were determined by plaque assay using MDCK cells. Briefly, $200 \mu \mathrm{l}$ of serially diluted virus in VGM was inoculated onto confluent MDCK cells in 24-well plates. After a $30 \mathrm{~min}$ absorption period, $0.8 \mathrm{ml}$ of overlay was added ( $0.6 \%$ Tragacanth in VGM). After $48 \mathrm{~h}$ of incubation the overlay was removed, the cells washed with cold PBS, fixed with cold acetone:methanol (1:1), and stained with crystal violet.

\section{Statistical analyses}

Statistical analyses were performed with PRISM ${ }^{\circledast}$ software (Graphpad Software, San Diego, CA). Significant differences between means were determined using unpaired Student's t-tests with 95\% confidence intervals.

\section{Assay for cell proliferation}

To evaluate the effects of TMP on cell proliferation we utilized the CyQUANT Cell Proliferation Assay Kit (Molecular Probes, Eugene OR). Briefly, cells were seeded in triplicate at a density of $5 \times 10^{3}$ cells/well in 96 well plates and allowed to adhere for $24 \mathrm{~h}$. Treatments were then performed and the plates processed according to manufacturer's instructions. The fluorescence intensity of CyQUANT GR dye, which is proportional to cellular DNA content, was then measured using the PolarStar microplate reader (BMG Labtechnologies, Durham, NC). 


\section{Assay for apoptosis}

An assay for active caspase-3 (Cayman Chemical Co., Ann Arbor MI, \#10009135) was used to monitor the apoptosis-inducing activity of TMP. Briefly, RAW 264.7 cells were plated in 96 well tissue culture plates and treated with TMP for $24 \mathrm{~h}$. Then, according to the manufacturer's instructions, the medium was removed, cells washed and lysis buffer added. A substrate for active caspase 3 (N-AcDEVD-N-MC-R110) was then added which, when cleaved by caspase 3, generates a fluorescent product with an emission maximum of $535 \mathrm{~nm}$. Positive and negative controls were supplied by the manufacturer. All points were performed in triplicate and values shown are means +/SEM.

\section{Results \\ TMP and prostaglandin production}

The goal of this set of experiments was to determine whether TMP can inhibit production of prostaglandins from RAW 264.7 macrophage-like cells. These cells have been used extensively as a model for prostaglandin production by primary macrophages [32-34]. As shown in Fig. 1A, we found that treatment of RAW 264.7 cells with $1 \mu \mathrm{g} / \mathrm{ml}$ of LPS induced robust $\mathrm{PGE}_{2}$ production. $\mathrm{PGE}_{2}$ was first detected 4-6 h after treatment with LPS began, and levels continued to rise during the remainder of the treatment period. Fig. 1A also shows that TMP at $25 \mu \mathrm{M}$ strongly inhibited production of $\mathrm{PGE}_{2}$. This effect was apparent early and maintained throughout the $16 \mathrm{~h}$ incubation period. As shown in Fig. 1B, we found that TMP displayed concentration-dependent inhibition of prostaglandin production. Typically, a $10 \mu \mathrm{M}$ concentration of TMP inhibited $\mathrm{PGE}_{2}$ production by approximately $60 \%$ while levels of inhibition reached $80-90 \%$ with $25 \mu \mathrm{M}$ TMP.

Our experiments showed that the inhibitory effect of TMP was not selective for production of $\mathrm{PGE}_{2}$. As shown in Figs. 1C and 1D, $25 \mu \mathrm{M}$ TMP inhibited the LPS-induced production of $\mathrm{PGF}_{2 \alpha}$ and $\mathrm{PGI}_{2} /$ prostacylin (as measured by production of the $\mathrm{PGI}_{2}$ hydration product 6-keto$\left.\mathrm{PGF}_{1 \alpha}\right)$. In addition, we found that the inhibitory effects of TMP are not specific for LPS-induced prostaglandin production. TMP inhibited production of $\mathrm{PGE}_{2}$ when PMA (Fig. 1E) or the influenza A virus PR/8/34 (Fig. 1F) were used as agonists. Finally, it should be noted that in all the experiments shown in Fig. 1, TMP and LPS were added simultaneously to the RAW 264.7 cells. Several experiments were performed in which the RAW 264.7 cells were pretreated with TMP (for up to several hours) but we did not find any enhanced suppression of $\mathrm{PGE}_{2}$ production following treatment with LPS (data not shown).
TMP and its effects on the expression and activity of COX-2 Our next set of experiments was designed to understand the molecular mechanism by which TMP inhibited prostaglandin production. TMP's ability to inhibit the production of different prostaglandins, and to inhibit the production of $\mathrm{PGE}_{2}$ induced by different agonists, suggested that TMP was likely acting on a common, downstream element of the prostaglandin biosynthetic pathway, such as cytosolic phospholipase $\mathrm{A}_{2}\left(\mathrm{cPLA}_{2}\right)$ [35] or COX-2 [36,37]. As shown in Fig. 2A, we found that TMP failed to inhibit the LPS-induced release of $\left[{ }^{3} \mathrm{H}\right]$-arachidonic acid from prelabeled cells. In fact, $\left[{ }^{3} \mathrm{H}\right]$-arachidonic acid release was actually enhanced by TMP. These results are consistent with TMP exerting a block in arachidonic acid metabolism downstream from $\mathrm{cPLA}_{2}$. Therefore, a series of experiments was performed to examine the effects of TMP on the expression and activity of COX2. Initially, we examined the effects of TMP on the expression of COX-2 mRNA. As shown in Fig. 2B, we found that TMP reduced the LPS-induced expression of COX-2 mRNA, and a deficit of approximately $40 \%$ was evident after a $16 \mathrm{~h}$ treatment with LPS. However, the significance of this finding is unclear. As shown in Fig. 2C, we found that TMP caused only an approximate $20 \%$ reduction in COX-2 protein expression under the same conditions. Finally, we also tested whether TMP could directly inhibit the enzymatic activity of COX-2. An assay was established in which the activity of purified ovine COX-2, alone or in the presence of inhibitors, could be measured spectrophotometrically. As shown in Fig. 2D, we found that the activity of COX-2 was inhibited by $40-50 \%$ in the presence of $25 \mu \mathrm{M}$ TMP while inhibition of COX-2 activity was essentially complete in the presence $50 \mu \mathrm{M}$ TMP. The level of inhibition of COX-2 activity by $50 \mu \mathrm{M}$ TMP was comparable to that observed in the presence of $10 \mu \mathrm{M}$ NS-398, a well characterized inhibitor of COX-2 [38].

\section{The effects of TMP on cytokine production}

Macrophage derived cytokines are critical to a variety of inflammatory processes and, therefore, we sought to evaluate TMP's effect on cytokine production from RAW 264.7 cells. First, an antibody filter array was used to survey the effects of TMP on cytokine production. The array we used (mouse inflammatory antibody array 1, RayBiotech, Norcross, GA) simultaneously detects 21 cytokines and/or growth factors and 15 chemokines. The array also contains antibodies for tissue inhibitor of metalloprotease-1 (TIMP-1) and -2 (TIMP-2) and for soluble TNF receptors 1 (sTNF $R 1$ ) and 2 (sTNF R2). Images of representative arrays are shown in Fig. 3, while semi-quantitative data derived from these arrays are shown in Fig. 4. As shown in Figs. 3A and 4A, only the cytokine MIP- $1 \gamma$ (coordinates L5 and L6) was detected at substantial levels in supernatants from unstimulated RAW 264.7 cells. We also found that treatment with TMP itself did not exert a strong 

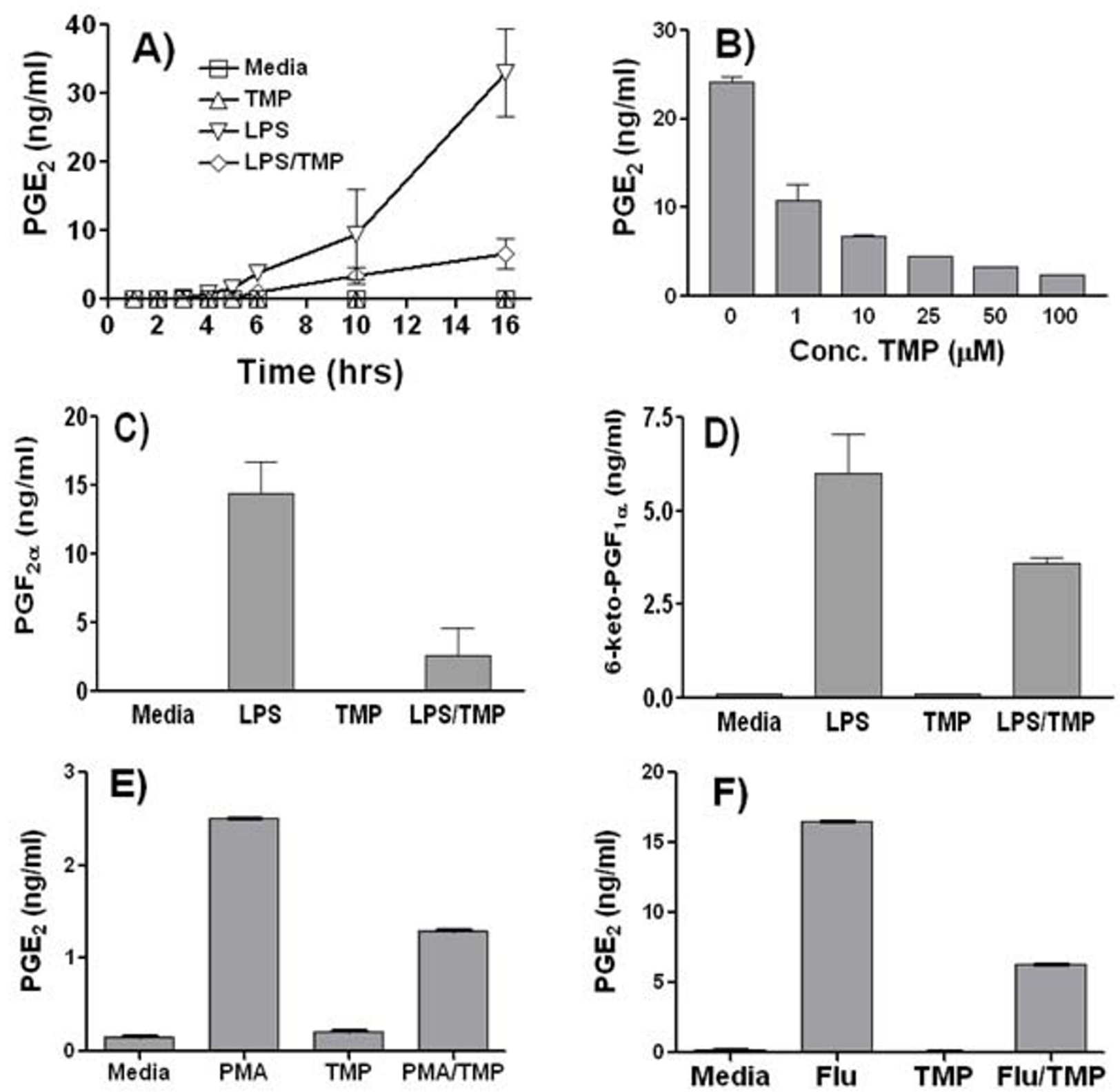

Figure I

Inhibition of prostaglandin production by TMP. RAW 264.7 cells were incubated with LPS and/or TMP for the indicated times and then $P_{G} E_{2}$ concentrations in culture supernatants were determined by ELISA (A). RAW 264.7 cells were incubated with LPS in the presence of increasing concentrations of TMP and PGE ${ }_{2}$ concentrations were determined by ELISA (B). RAW 264.7 cells were left untreated (Media) or treated with LPS and/or TMP and the concentrations in culture supernatants of PGF $_{2 \alpha}(\mathrm{C})$ and 6-keto-PGF ${ }_{1 \alpha}(\mathrm{D})$ were determined by ELISA. RAW 264.7 cells were left untreated (Media) or treated with PMA $(10 \mathrm{ng} / \mathrm{ml})(E)$ or influenza $A$ virus PR/8/34 (5 pfu/cell) $(F)$ in the presence or absence of TMP and PGE $\mathrm{E}_{2}$ concentrations in culture supernatants were determined by ELISA. Unless otherwise indicated concentrations of LPS and TMP were I $\mu g / \mathrm{ml}$ and $25 \mu \mathrm{M}$, respectively, and the incubation time was $16 \mathrm{~h}$. Panels $A$ and $B$ show representative experiments while the other panels show the mean \pm SEM from 3 experiments. All samples were assayed in duplicate and error bars are less than symbol size where not shown. TMP was added simultaneously in experiments with LPS or PMA while TMP was added $30 \mathrm{~m}$ after infection with influenza $A$. In panels $C-F$, asterisks indicate significant differences between treatments with inducing agents alone and inducing agents with TMP ( $P<0.05$, Student's t-test). 

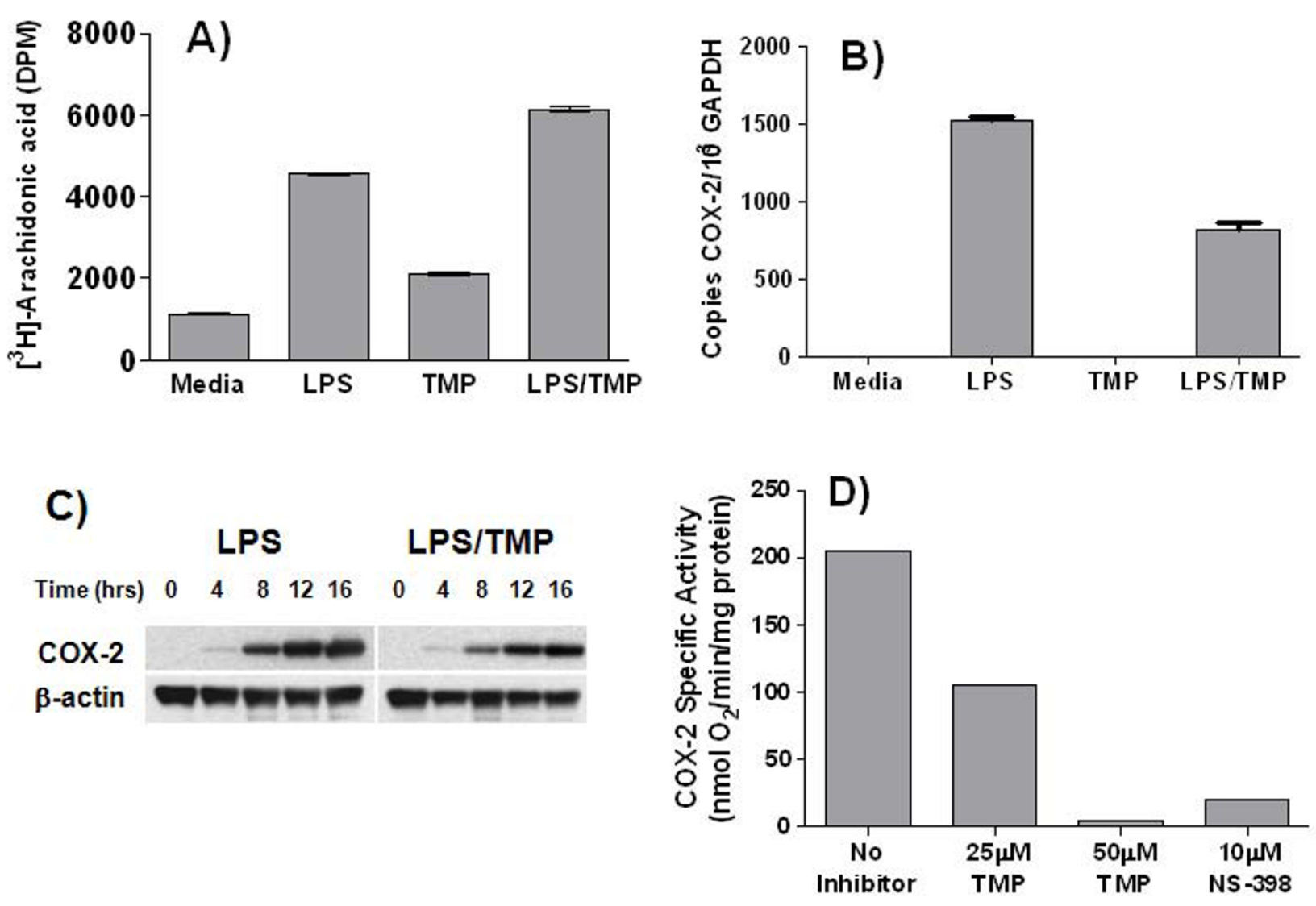

Figure 2

The effects of TMP on expression and activity of COX-2. RAW 264.7 cells were labeled overnight with [ $\left.{ }^{3} \mathrm{H}\right]$-arachidonic acid, washed, then either left untreated (Media), or treated with LPS (I $\mu \mathrm{g} / \mathrm{ml})$ and/or TMP $(25 \mu \mathrm{M})$ for I6 h (A). Supernatants were collected and radioactivity determined by scintillation counting. RAW 264.7 cells were treated with LPS (I $\mu$ g/ml) alone or in combination with TMP $(25 \mu \mathrm{M})$ and copy number of COX-2 mRNA determined by q-RT-PCR as described in the Materials and Methods (B). RAW 264.7 cells were treated with LPS (I $\mu \mathrm{g} / \mathrm{ml})$ and/or TMP $(25 \mu \mathrm{M})$, and the expression of COX-2 protein was examined by Western blot $(\mathrm{C})$. TMP was added to purified placental ovine COX-2 protein and specific activity determined as described in the Materials and Methods (D).

effect on this profile (Figs. 3B and 4B). Subtle changes, both increases and decreases, were seen in the levels of several cytokines and again only MIP- $1 \gamma$ was detected at high levels.

As expected, we found that stimulation of RAW 264.7 cells with $1 \mu \mathrm{g} / \mathrm{ml}$ LPS dramatically enhanced the production of a number of cytokines and chemokines (Figs. 3C and 4C). For purposes of discussion we have divided these into two groups. One group of cytokines and chemokines was induced to high levels, with mean pixel densities within $75 \%$ of the positive controls included with the array kit. The coordinates on the array of these cytokines and chemokines are enclosed by solid ellipses in Fig. 3. Included in this group are RANTES (A7/8), TNF- $\alpha$ (G7/8), IL-6 (H3/4), MCP-1 (H5/6), MIP-1 $\alpha$ (K5/6), and G-CSF
(L1/2). A second set of cytokines, including; GM-CSF (A3/ 4), IL-1 $\alpha$ (C3/4), M-CSF (I5/6), and IL-12p40p70 (K3/4) was induced to a lesser degree. The coordinates of these cytokines are enclosed by dashed ellipses in Fig. 3. Mean pixel densities for cytokines in this group were typically between 20-25\% above negative controls. Finally, we found that LPS also triggered an increase in the production of TIMP-1 (E7/8) and sTNF R2 (I7/8).

As shown in Figs. 3D and 4D, we found that TMP exerted a range of effects on LPS-induced cytokine production. Among the cytokines normally induced by LPS to high levels; TMP produced two levels of suppression. Very slight suppression was noted for two cytokines, IL-6 $(11 \%)$ and MIP-1 $\alpha(8 \%)$, while substantially higher levels of suppression were noted for RANTES (29\%), G-CSF 


\section{A) Media}

\section{B) TMP}

\section{A B C D EFG H I J K L A B C D F G H I J K L}

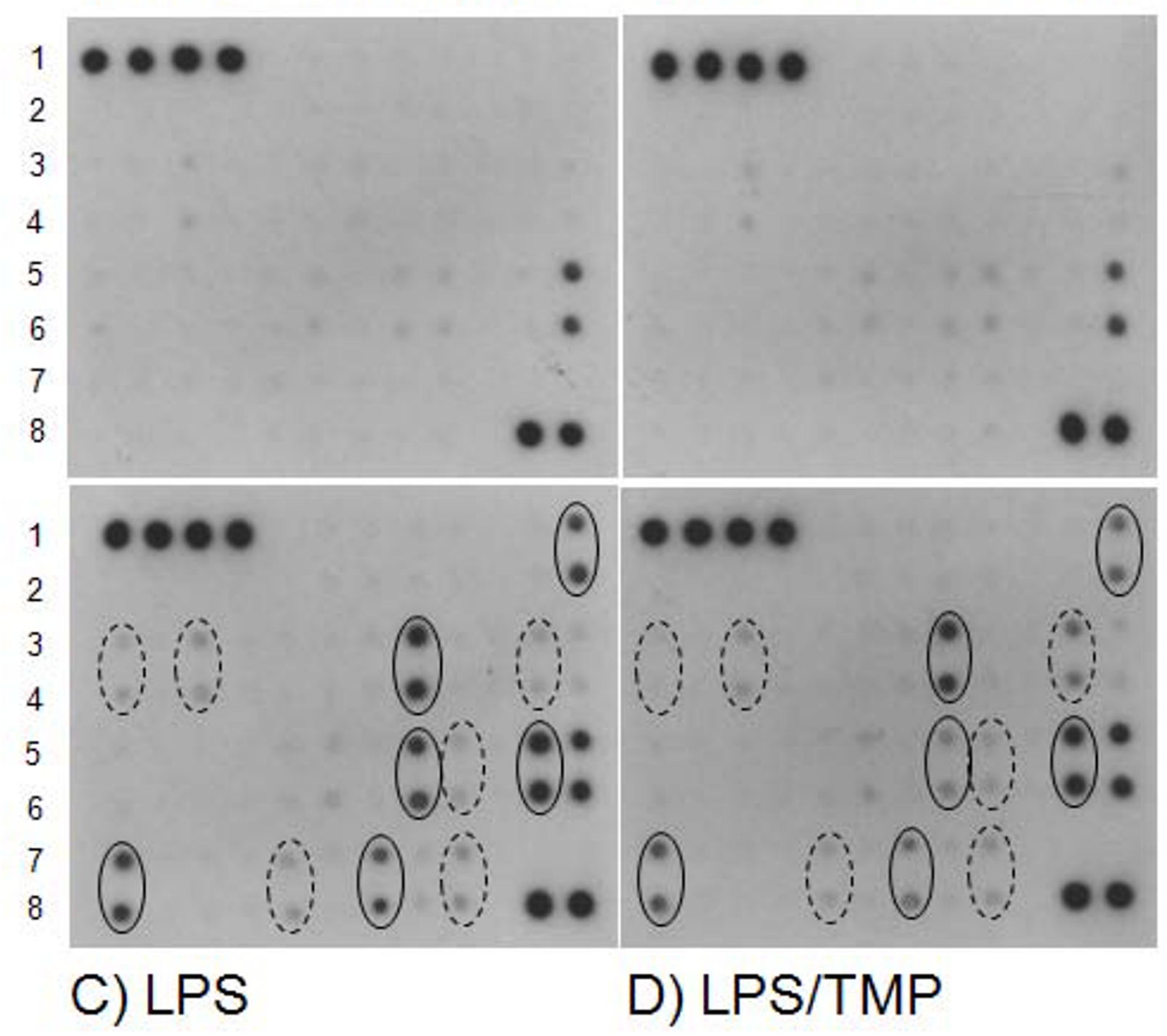

\section{Figure 3}

The effects of TMP on cytokine production. RAW 264.7 supernatants were collected and assayed for cytokine production using the Mouse Cytokine Array I (RayBiotech, Norcross GA). Shown in this figure are scans of films developed from array filters following incubation with supernatants from either untreated control cells $(A)$, or from cells following incubation with $25 \mu$ M TMP (B), I $\mu \mathrm{g} / \mathrm{ml}$ LPS (C), or $25 \mu \mathrm{M}$ TMP and I $\mu \mathrm{g} / \mathrm{ml}$ LPS (D). All supernatants were collected following a I6 $\mathrm{h}$ incubation period. The cytokines, chemokines, growth factors, and inflammatory products detected by the array and their respective coordinates are: Eotaxin, HI/2; Eotaxin-2, II/2, Fas Ligand, JI/2; Fractalkine, KI/2; GCSF, LI/2; GM-CSF, A3/4; IFN$\gamma$, B3/4; IL-I $\alpha$, C3/4; II- I $\beta$, D3/4; IL-2, E3/4; IL-3, F3/4; IL-4, G3/4; IL-6, H3/4; IL-9, I3/4; IL- I0, J3/4; IL-I2p40p70, K3/4; IL- I2p70, L3/4; IL-I3, A5/6; IL-I7; B5/6; I-TAC, C5/6; KC, D5/6; Leptin, E5/6; LIX, F5/6; Lymphotactin, G5/6; MCP-I, H5/6; M-CSF, I5/6; MIG, J5/6; MIP-I $\alpha$, K5/6; MIP-I $\gamma$, L5/6; RANTES, A7/8; SDF-I, B7/8; TCA-3, C7/8; TECK, D7/8; TIMP-I, E7/8; TIMP-2, F7/8; TNF- $\alpha$, G7/8, sTNF RI, H7/8; sTNF R2, I7/8. Positive controls are located at positions AI, BI, CI, DI, K8, and L8. Negative controls are located at positions A2, B2, C2, and D2. Blanks are located at positions EI, E2, J7, J8, K7, and L7. Solid and dashed ellipses indicate the coordinates of cytokines and chemokines induced by LPS to high and low levels, respectively, as discussed in the text. 
(36\%), TNF- $\alpha$ (43\%), and MCP-1 (58\%). TMP also exerted a range of effects on the cytokines produced at lower levels. Production of GM-CSF was blocked completely, while slight suppression was noted for IL- $1 \alpha$ $(16 \%)$. In contrast, secretion of M-CSF was increased to a small degree (7\%), and that of IL-12p40p70 was increased substantially (141\%). TMP also inhibited production of TIMP-1 (36\%) and sTNF R2 (30\%).

Since antibody filter arrays are typically semi-quantitative, we sought to confirm several of the effects we had noted using specific cytokine ELISAs. As shown in Fig. 5A, suppression of TNF- $\alpha$ production measured by ELISA (42\%) very closely matched the level of suppression observed on the array (43\%). The suppressive effects of TMP were also very similar for MCP-1 production, when measured by ELISA (Fig. 5B) (67\%) or by the array (58\%). On the other hand, ELISA did not confirm the inhibition of RANTES production (Fig. 5C) noted on the array. At present, the reason for this discrepancy is unclear. Finally, we also used ELISA to investigate the TMP-dependent increase in IL-12p40p70. The increase in IL12p40p70 noted on the array, in the absence of an increase in IL-12p70 (Figs. 3D and 4D), suggests that TMP enhances the LPS-dependent production of $\mathrm{p} 40$ monomers or homodimers. Alternatively, it is also possible that this represents production of IL-23 since $\mathrm{p} 40$ is also a component of IL-23. As shown in Fig. 5D, an ELISA specific for IL-12p40 confirmed the finding from the array. However, an ELISA specific for IL$23(\mathrm{n}=3,10 \mathrm{pg} / \mathrm{ml}$ sensitivity) did not detect any of this cytokine (data not shown). We conclude, therefore, that these supernatants contain either monomers or homodimers of $\mathrm{p} 40$.

\section{TMP and its effects on cytokine mRNAs}

Next, a series of experiments was performed to define the mechanism by which cytokine production was inhibited by TMP. Specifically, we used quantitative RT-PCR to investigate the effects of TMP on production of cytokine mRNA. As shown in Fig. 6, we found a strong correlation between the effects of TMP on cytokine protein levels, as measured by ELISA, and expression of cytokine mRNA. Levels of TNF- $\alpha$ protein and mRNA were reduced by 42 and $40 \%$, respectively; while levels of MCP-1 protein and mRNA were reduced by 67 and 76\%, respectively. Similarly, neither RANTES mRNA (Fig. 6C) nor protein (Fig. $5 \mathrm{C}$ ) levels were suppressed by TMP. In fact, we measured a small increase in RANTES mRNA following treatment with TMP and LPS (Fig. 6C).

The effect of TMP on production of $P G E_{2}$, cytokines, and chemokines by peritoneal macrophages

To further substantiate the results of our experiments with RAW 264.7 cells, a set of experiments was performed with normal mouse macrophages. Resident peritoneal macro- phages were harvested from $\mathrm{C} 57 \mathrm{BL} 6 / \mathrm{J}$ mice, then treated with LPS and/or TMP in vitro, and cell supernatants were examined for $\mathrm{PGE}_{2}$ and several cytokines. As shown in Fig. 7 , the results of these experiments were highly similar to those seen with RAW 264.7 cells. Levels of PGE ${ }_{2}$, TNF- $\alpha$, and MCP-1 produced by peritoneal macrophages were all reduced by TMP to extents comparable to those seen in experiments with the RAW 264.7 cell line. The exception was the effect of TMP on the production of IL-12/23 p40. TMP did not enhance IL-12/23 p40 production from LPStreated peritoneal macrophages as it did with LPS-treated RAW 264.7 cells. Instead, levels of IL-12p40 were reduced by approximately $60 \%$.

\section{The effect of TMP on production of cytokines in vivo}

The finding that TMP inhibits production of TNF- $\alpha$ in vitro raises the possibility that TMP may be useful in vivo in a variety of inflammatory conditions. To test whether TMP can inhibit the production of TNF- $\alpha$ in vivo we established a transient endotoxemia model in C57BL6/J mice [39]. The mice were injected i.p. with $20 \mu \mathrm{g}$ of LPS in the CPE vehicle which caused the animals mild distress; the mice huddled for 2-3 hours then returned to normal behavior. We also found, as has been reported [39] that this dose of LPS induced a transient increase in levels of serum TNF- $\alpha$. Serum levels of TNF- $\alpha$ peaked $2-3 \mathrm{~h}$ after injection with LPS and returned to pre-injection levels by 1-2 h later (data not shown). Two experiments were then performed in which TMP was administered in the CPE vehicle followed $1 \mathrm{~h}$ later by LPS. Serum was collected $3 \mathrm{~h}$ after the LPS challenge and levels of TNF- $\alpha$ were determined by ELISA. The results from the first of these experiments are shown in Fig. 8A. As expected, we measured low levels of TNF- $\alpha$ in the serum of mice that received PBS $(19 \pm 3 \mathrm{pg} /$ $\mathrm{ml}$; mean \pm SEM), CPE vehicle $(60 \pm 9 \mathrm{pg} / \mathrm{ml})$, or TMP in the CPE vehicle $(49 \pm 9)$. Much higher levels of TNF- $\alpha$ were measured in mice first treated with the CPE vehicle followed by LPS in PBS (657 \pm 50$)$; and, strikingly, we found that TMP offset this increase by $41 \%(385 \pm 19 \mathrm{pg} /$ $\mathrm{ml})$.

We also examined these serum samples for $\mathrm{PGE}_{2}$ using an ELISA kit that permits measurements of $\mathrm{PGE}_{2}$ in mouse serum (\#P9053-30, USBiological, Swampscott MA). The results of these assays did not reveal any significant changes in $\mathrm{PGE}_{2}$ concentration in any treatment group. Levels of $\mathrm{PGE}_{2}$ varied from $2.5-5.0 \mathrm{ng} / \mathrm{ml}$ per mouse in the PBS injected mice and remained in that range in groups treated with TMP in CPE vehicle, CPE vehicle followed by LPS, and TMP in CPE vehicle followed by LPS (data not shown).

A second experiment was then performed to confirm the effects of TMP on production of TNF- $\alpha$. Overall, the results were highly similar to those in the first experiment. We 

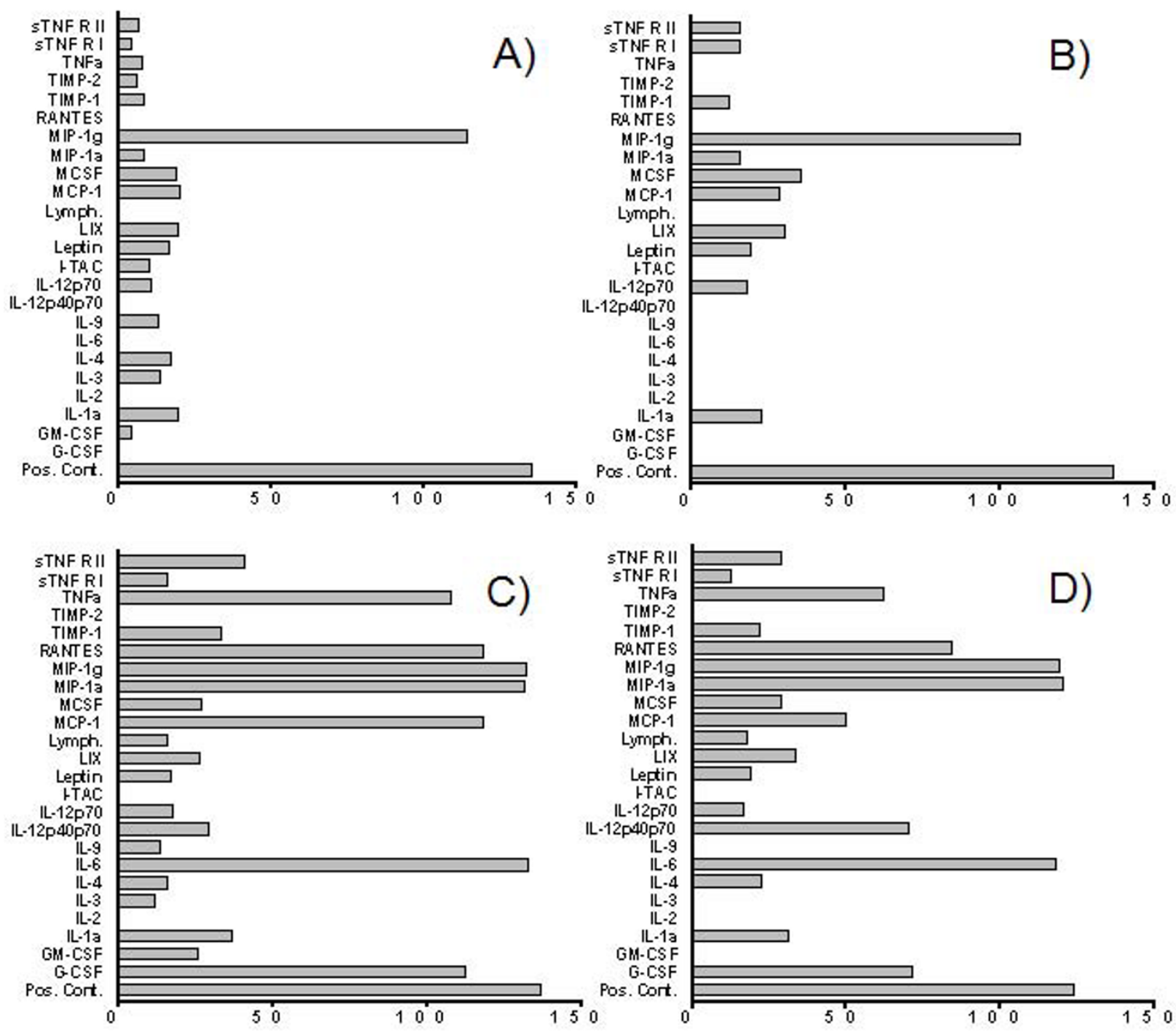

\section{Figure 4}

The effects of TMP on cytokine production. Images of the arrays shown in Fig. 3 were analyzed using Photoshop (Adobe) and mean pixel intensity ( $\mathrm{x}$-axis) determined for each array position. Supernatants were collected from untreated control cells (A), or from cells following incubation with $25 \mu \mathrm{M}$ TMP (B), I $\mu \mathrm{g} / \mathrm{ml}$ LPS (C), or $25 \mu \mathrm{M}$ TMP plus I $\mu \mathrm{g} / \mathrm{ml}$ LPS (D). Mean intensity values are plotted for the 24 products which were detected under one or more of the experimental conditions. SEM was less than $5 \%$ for each pair of array positions.

found low levels of TNF- $\alpha$ in the serum of mice treated with PBS $(21 \pm 21 \mathrm{pg} / \mathrm{ml})$, higher levels with LPS treatment following installation of the CPE vehicle $(430 \pm 39)$ and significant suppression with TMP $(42 \%)(251 \pm 52 \mathrm{pg} / \mathrm{ml}$, $\mathrm{p}<0.05$, Student's t-test). In this experiment, rather than test for $\mathrm{PGE}_{2}$, we quantified levels of MCP-1. Our results showed significant suppression (27\%) by TMP of the LPSinduced accumulation of MCP-1 in serum (Fig. 8B).

\section{The effects of TMP on the growth of RAW 264.7 cells}

Experiments summarizing the effects of TMP on the growth of RAW 264.7 macrophage-like cells are shown in
Fig. 9. Using an assay that monitors DNA accumulation (Cyquant) (Fig. 9A) we found that the growth of RAW 264.7 cells was inhibited at the higher concentrations of TMP tested. For example, growth of RAW 264.7 cells was inhibited by approximately $40 \%$ during a $24 \mathrm{~h}$ incubation with $25 \mu \mathrm{M}$ TMP. In contrast, as shown in Fig. 9B, we did not detect any apoptosis at this concentration of TMP. The lack of toxicity of TMP towards RAW 264.7 cells was confirmed in experiments where RAW 264.7 cells were transiently exposed to $25 \mu \mathrm{M}$ TMP. As shown in Fig. 9C, when TMP is withdrawn following a $24 \mathrm{~h}$ exposure, the cells quickly regain their normal rate of growth. 

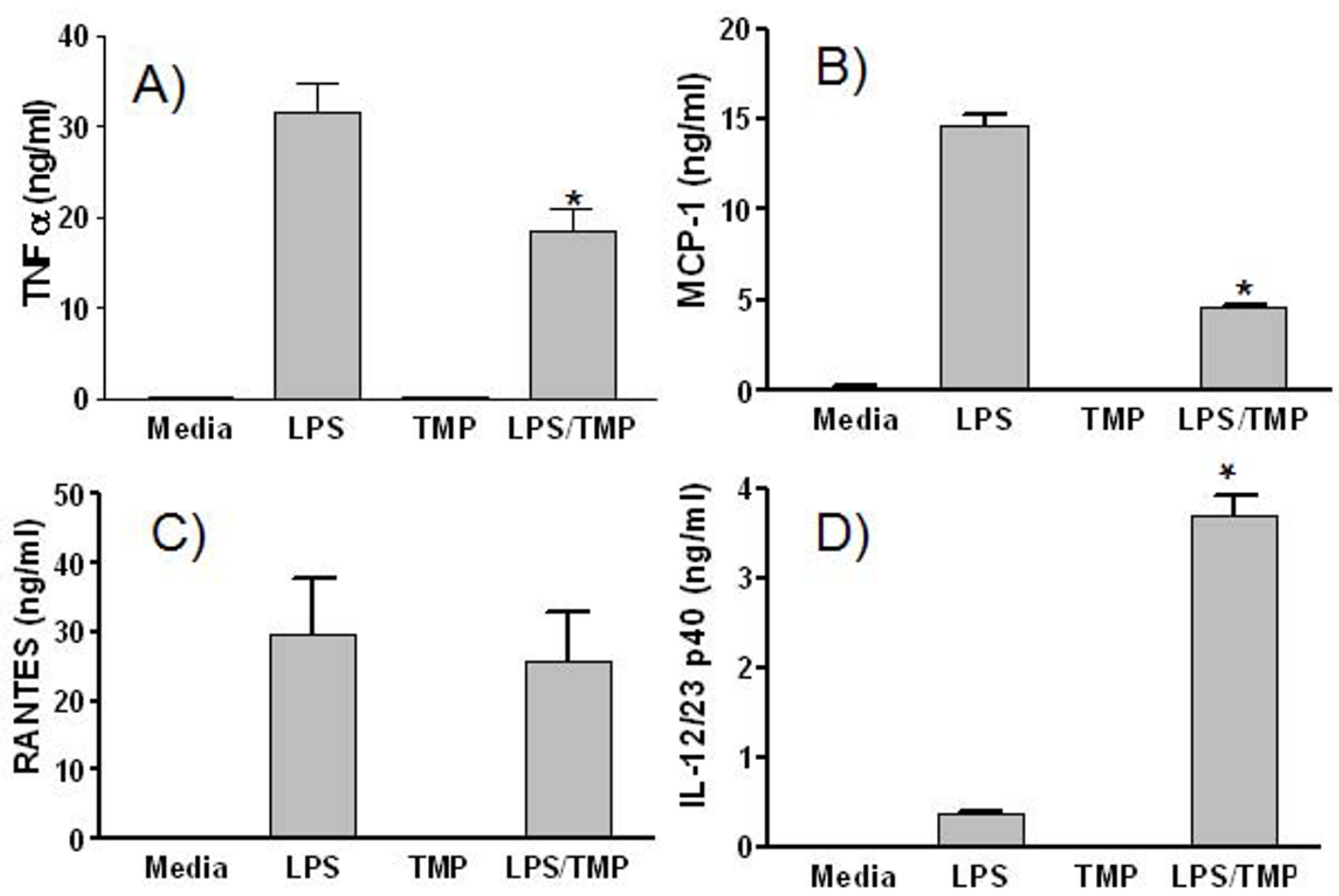

Figure 5

The effects of TMP on cytokine production measured by ELISA. RAW 264.7 cells were left untreated (Media), or treated with either I $\mu \mathrm{g} / \mathrm{ml}$ LPS and/or $25 \mu \mathrm{M}$ TMP for $16 \mathrm{~h}$. Culture supernatants were then analyzed by ELISA for TNF- $\alpha$ (A), MCP-I (B), RANTES (C), or IL-I2/23 p40 (D). All samples were assayed in duplicate and values shown are means \pm SEM from $2-3$ independent experiments. Asterisks indicate significant differences between treatments with LPS alone vs. LPS with TMP ( $P$ $<0.05$, Student's t-test).

\section{Discussion}

Chronic activation or hyper-activation of the innate immune system is the cause of many damaging inflammatory and auto-immune pathological reactions. The secretory products of activated macrophages are major contributors to these reactions. Our goal in these studies was to test whether TMP can inhibit the production of macrophage derived pro-inflammatory cytokines and lipids. Our impetus was twofold; to better understand the mechanisms underlying the traditional anti-inflammatory uses for L. tridentata, and to determine whether a safe, potentially effective anti-cancer drug might have an alternative use. The results of our experiments showed that TMP can indeed inhibit the production of several key macrophage products. Production of prostaglandins was suppressed as was the production of certain cytokines and chemokines raising the possibility that it may indeed be useful to treat inflammation. Clearly, further study will be necessary to determine the extent to which naturally occurring tetra-O-methyl NDGA contributes to the antiinflammatory activity found in extracts of $L$. tridentata.

Excess prostaglandin production has been linked to a variety of inflammatory responses and auto-immune pathological reactions. $\mathrm{PGE}_{2}$, for example, has been linked to production of amyloid- $\beta$ peptides in Alzheimer's disease [40], while both $\mathrm{PGE}_{2}$ and $\mathrm{PGI}_{2} /$ prostacyclin have been linked to joint destruction during rheumatoid arthritis [41,42]. Our experiments revealed broad suppression of prostaglandin production by TMP in vitro with levels of $\mathrm{PGE}_{2}, \mathrm{PGF}_{2 \alpha^{\prime}}$ and $\mathrm{PGI}_{2} /$ prostacyclin all being reduced. These results are consistent with those of early studies 

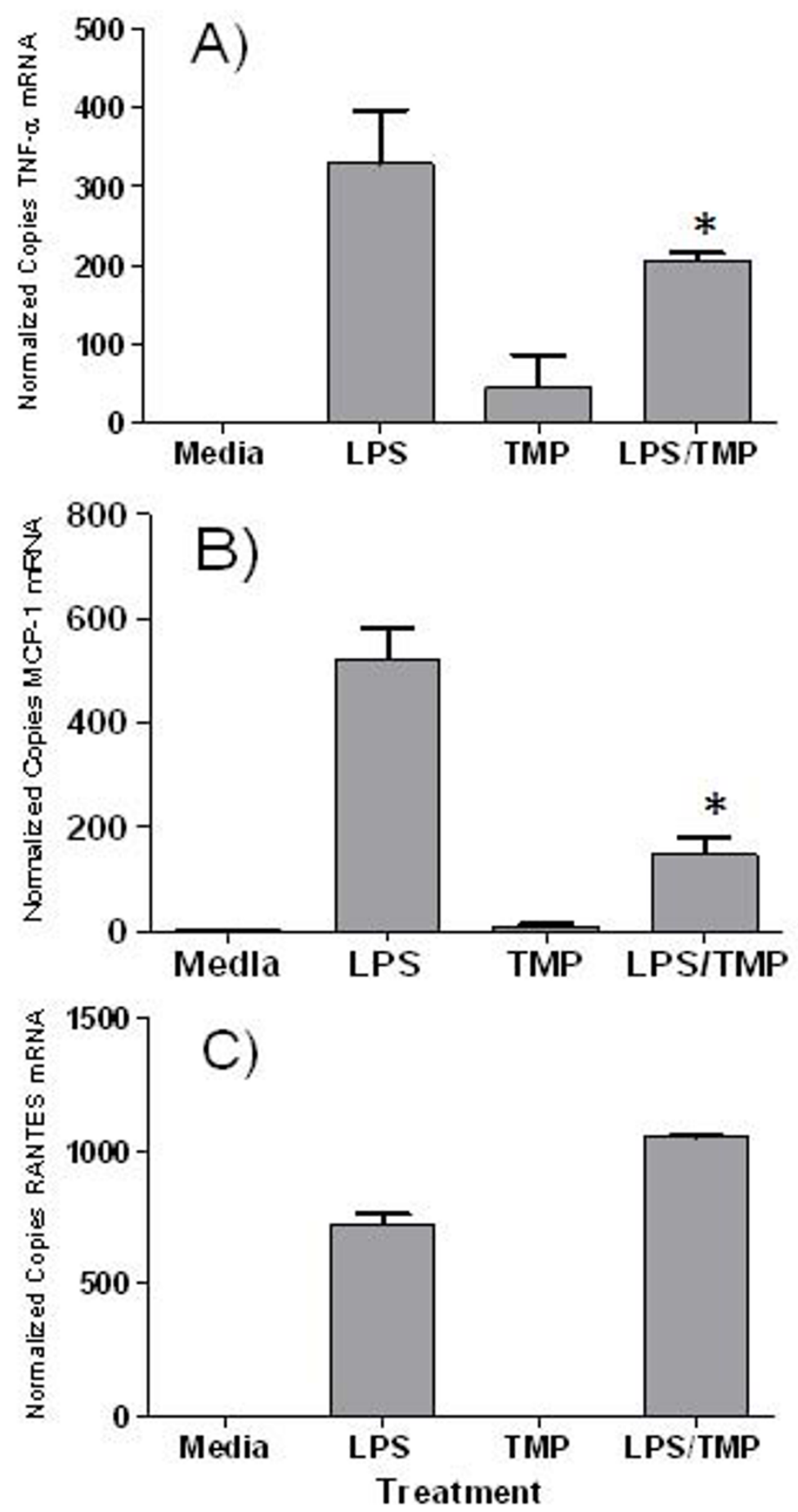

\section{Figure 6}

The effects of TMP on copy number of cytokine mRNA. RAW 264.7 cells were left untreated (Media), or treated with LPS $(I \mu \mathrm{g} / \mathrm{ml})$ and/or TMP $(25 \mu \mathrm{M})$. After $16 \mathrm{~h}$, total RNA was extracted from the cell pellet and mRNA copy number determined by q-RT-PCR for TNF- $\alpha(A)$, MCP-I (B) and RANTES (C). Panels show means \pm SEM of representative experiments with duplicate copy number determinations performed in each experiment. Asterisks indicate significant differences between treatments with LPS and LPS/TMP ( $P<0.05$, Student's t-test). 

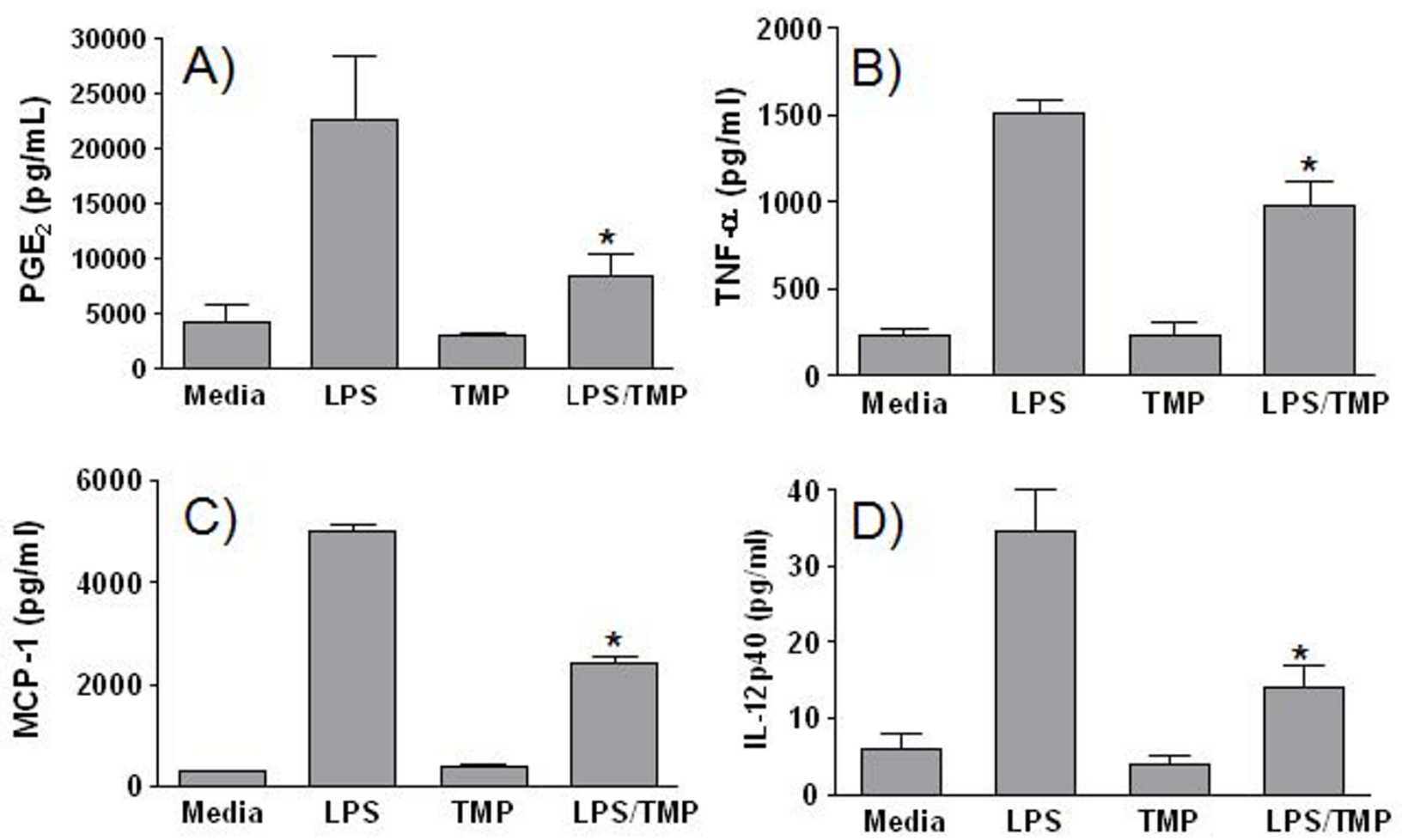

\section{Figure 7}

The effects of TMP on cytokine, chemokine and inflammatory lipid production by peritoneal macrophages. Macrophages were collected from C57BL6/J mice and left either untreated (Media), or treated overnight with I $\mu$ g/ml LPS and/ or $25 \mu$ M TMP. Levels of PGE 2 (A), TNF- $\alpha(B)$, MCP-I (C) and IL-I2/23 p40 (D) in cell culture supernatants were subsequently determined by ELISA. Panels show means \pm SEM from 2-3 experiments for each mediator. Asterisks indicate significant differences between treatments with LPS and LPS/TMP ( $p<0.05$, Student's t-test).

which showed that NDGA, the parent compound of TMP, could suppress prostaglandin production by primary murine macrophages $[43,44]$. Our results suggested that TMP may indeed be useful clinically to treat a number of disorders and, therefore, we investigated the mechanism underlying this activity. Because prostaglandin production was suppressed regardless of the inducing agent (LPS, phorbol ester, or influenza virus), we reasoned that it was unlikely that TMP was interfering with signals from specific receptors such as TLR-4 [35]. Therefore we focused our investigation on common, downstream elements in the prostaglandin pathway such as $\mathrm{CPLA}_{2}[35]$, and COX$2[36,37]$. TMP did not inhibit the LPS-induced release of $\left[{ }^{3} \mathrm{H}\right]$-arachidonic acid, which suggested that it was not affecting the activity of $\mathrm{CPLA}_{2}$, and therefore we focused our efforts on COX-2. Our experiments revealed a number of effects of TMP on COX-2, including; a $40 \%$ reduction in COX-2 mRNA, a 20\% reduction in COX-2 protein, and inhibition of COX-2 enzymatic activity. The effects of TMP on the expression of COX-2 mRNA were not entirely surprising since the 5 ' flanking region of the COX-2 gene has 3 Sp1 binding sites [45] and TMP is known to inhibit
Sp1 binding to DNA [24]. Exactly how TMP's effect on the expression of COX-2 mRNA ultimately impacts prostaglandin production is not clear. The decrease in COX-2 mRNA resulted in only a modest decrease in COX-2 protein making it unlikely that this effect of TMP is a major determinant of its ability to suppress prostaglandin production. Rather, it seems that a direct inhibitory effect of TMP on COX-2 enzymatic activity is primarily responsible for the suppression of prostaglandin synthesis. This result was unexpected. Although NDGA, the parent compound of TMP, is widely known as an inhibitor of lipoxygenases, direct inhibition of COX-2 activity by NDGA appears not to have been described. In addition, lipoxygenase inhibition by NDGA is thought to depend on its anti-oxidant activity, but this is greatly reduced in TMP, which carries methyl rather than hydroxyl groups. Clearly, more studies need to be performed to examine the interaction between COX-2 and TMP and elucidate the mechanism of inhibition.

Our results suggest that TMP is a potent, direct inhibitor of COX-2 activity, and the magnitude of this effect may be 

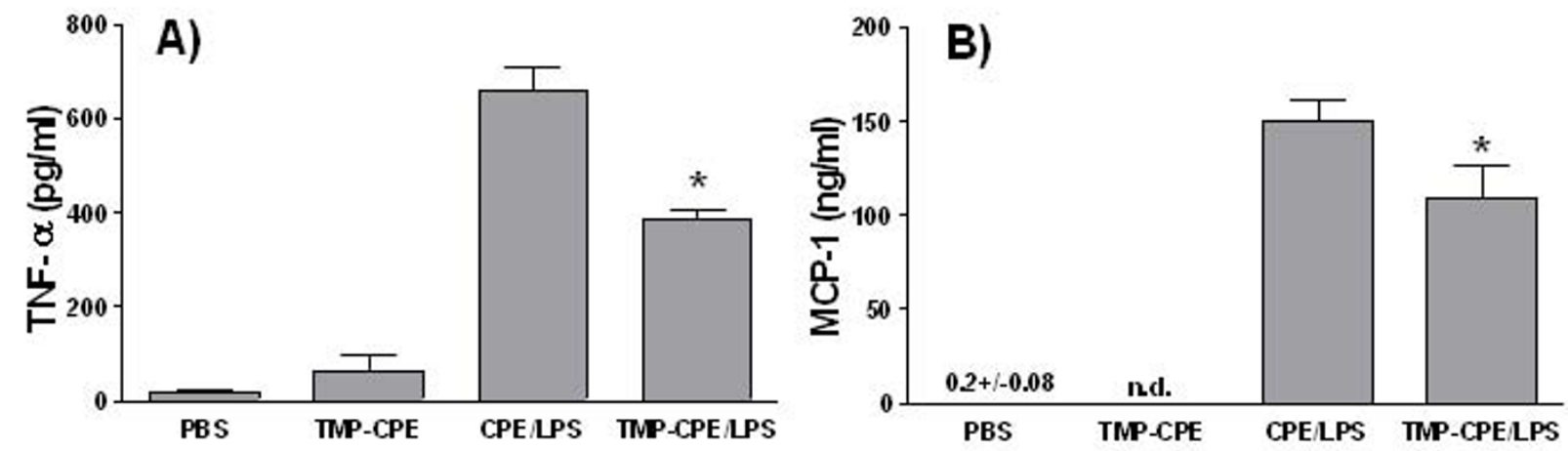

\section{Figure 8}

The effects of TMP on serum levels of TNF- $\alpha$ and MCP-I. C57BL6/J mice (5/treatment) were used in a transient endotoxemia model to test TMP's ability to inhibit cytokine and chemokine production in vivo. One group of mice was injected only with PBS while a second group received only TMP $(\mathrm{I} \mathrm{mg})$ in the CPE vehicle. Serum was collected from these mice after $4 \mathrm{~h}$. A third group received the CPE vehicle followed I h later by $20 \mu \mathrm{g}$ of LPS while a fourth group received I mg of TMP in the CPE vehicle followed I hr later by $20 \mu \mathrm{g}$ of LPS. Serum was collected from these mice $3 \mathrm{~h}$ after the LPS injection. Levels of TNF- $\alpha$ and MCP-I were determined by ELISA. Panels show means \pm SEM from representative experiments. Asterisks indicate significant differences between treatments with CPE vehicle followed by LPS and TMP in CPE vehicle followed by LPS ( $P<0.05$, Student's t-test). n.d. - not determined.

sufficient to fully account for the suppression of prostaglandin production by TMP in LPS-stimulated cells. However, since the yield of the various prostaglandins tested was not affected equally by a fixed concentration of TMP, it is conceivable that TMP may also affect the activity of one or more of the prostaglandin synthases downstream from COX-2. Further research will be required to evaluate this possibility.

In this study we also addressed the effects of TMP on the LPS-induced production of cytokines and chemokines by RAW 264.7 cells. The antibody array we used revealed increases in the production of 10 cytokines or chemokines following treatment with LPS. We also measured increased levels of TIMP-1 and sTNF R2 in culture supernatants. Among these molecules, TMP failed to suppress production of the chemokine MIP- $1 \alpha$, or the cytokines IL6 , IL-1 $\alpha$, and M-CSF. On the other hand, suppression was noted for the chemokine MCP-1, and for the cytokines TNF- $\alpha$, G-CSF, and GM-CSF. We also noted suppression of production of TIMP-1 and sTNF R2. In contrast to the results obtained for COX-2, we found a strong correlation between the levels of cytokine mRNAs and their respective protein products. TMP suppressed the accumulation of TNF- $\alpha$ and MCP-1 mRNA and protein to similar extents, while it had no effect on the accumulation of RANTES mRNA or protein. The suppression of cytokine mRNA accumulation by TMP in LPS-stimulated cells may be determined by its ability to inhibit binding of the Sp1 transcription factor to DNA. Experiments with monocytic cell lines have shown that $S p 1$ binding sites are required for the LPS-induced activation of the TNF- $\alpha$ promoter [46], whereas they are completely dispensable for activation of the RANTES promoter [47]. Although a direct effect of TMP on cytokine gene transcription could account for the reduced accumulation of mRNAs, other, post-transcriptional mechanisms cannot be excluded. For example, TNF- $\alpha$ production can be regulated at the level of mRNA stability [48], as well as by protease cleavage of the TNF- $\alpha$ precursor [49], and either of these might be affected by TMP. Interestingly, if TMP inhibited the expression or activity of the TNF- $\alpha$ converting enzyme, it would be expected to reduce the levels of both secreted TNF- $\alpha$ [49] and sTNF R2 [50], as we observed in our experiments. Additional investigation will be required to fully elucidate the mechanisms by which TMP suppresses the production of various cytokines including its potential effects on other transcription factors linked to inflammation, such as NF-kB.

Overall, for testing the effects of TMP on cytokine production, the RAW 264.7 cell line proved to be an excellent model, although we did find one major difference in its response to LPS compared to that of peritoneal macrophages. Treatment with TMP caused an increase in the expression of IL-12/23 p40 in LPS-stimulated RAW 264.7 cells, but this effect was not seen with LPS-stimulated peritoneal macrophages. In peritoneal macrophages, we observed a response that was consistent with the effects of TMP on other cytokines; namely inhibition of expression. Why the LPS-dependent expression of IL-12/23 p40 is increased by TMP in RAW 264.7 cells is not clear. Appar- 

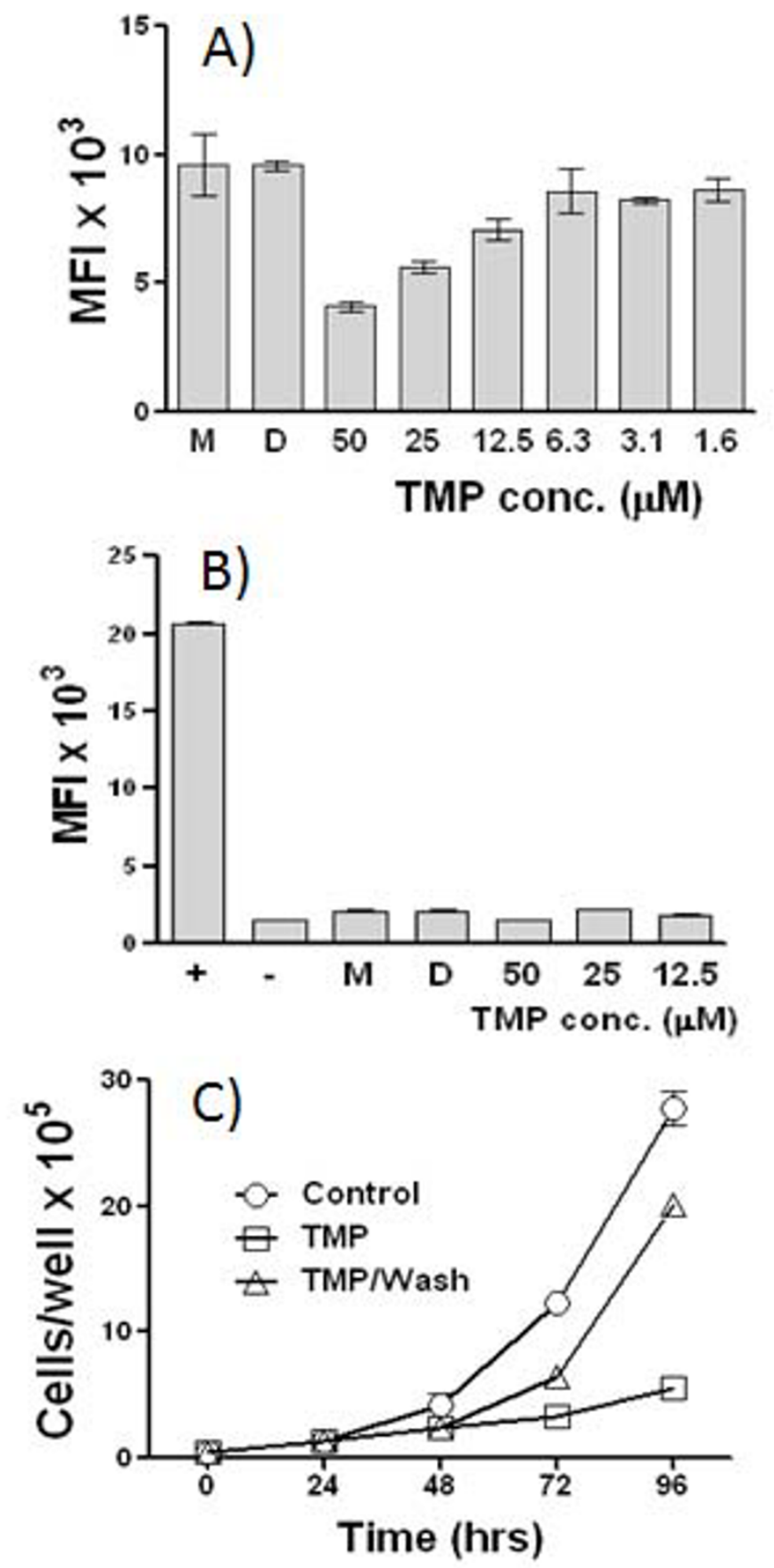

\section{Figure 9}

The effects of TMP on the growth and viability of RAW 264.7 cells. TMP was added to RAW 264.7 cells in vitro and their growth monitored for $24 \mathrm{~h}$ using the CyQuant proliferation assay (A). The induction of apoptosis in RAW 264.7 cells following a $24 \mathrm{~h}$ exposure to TMP was measured using an assay for active caspase 3 (Cayman) (B). In panels $A$ and $B, M$ and $D$ indicate media and DMSO controls. In panel B, + and - indicate the addition of positive and negative controls supplied by the manufacturer. In C, cells were plated in 24 well plates, allowed to adhere $24 \mathrm{~h}$, then washed and incubated with either fresh medium or medium containing $25 \mu \mathrm{M}$ TMP. After $24 \mathrm{~h}$, the medium containing TMP was removed from one set of wells, replaced with fresh medium without TMP, and the cells were incubated for an additional $48 \mathrm{~h}$. Cell counts were determined by hemocytometer. Values shown are means $+/-$ SEM and all points were performed in triplicate. 
ently, the pathway(s) that regulate the expression of IL$12 \mathrm{p} 40$ are altered in RAW 264.7 cells so that TMP causes an enhancing effect.

Our experiments also revealed that TMP inhibited the growth of RAW 264.7 cells. Based on the ability of TMP to inhibit the growth of certain tumor-derived cell lines, and its effects on Sp1, its effect on the growth of RAW 264.7 cells was not surprising. We did not detect any apoptosis and the growth inhibitory effect disappeared when the TMP was withdrawn, indicating that TMP is not damaging towards RAW 264.7 cells and is likely causing reversible, cell cycle arrest. In the future it will be interesting to determine whether there is a link between the growth inhibitory effects of TMP and the ability of TMP to inhibit production of cytokines and inflammatory lipids in RAW 264.7 cells. However, since peritoneal macrophages do not grow in vitro, we can conclude that growth inhibition is not a prerequisite for TMP to exert its anti-inflammatory effects.

Based on the ability of TMP to inhibit cytokine and lipid mediator production in vitro, we tested whether TMP could exert these effects in vivo. We used a mouse model of endotoxemia in which a sublethal dose of LPS is administered i.p. resulting in transient increases in the serum levels of several cytokines. Increased cytokine levels are evident within one hour; continue to rise for 2-3 hrs, then return to pretreatment levels 1-2 hrs later. The response to LPS under these circumstances is complex and cytokine production involves many cell types from different organs and tissues. LPS is transported from the peritoneum to the liver via the portal vein [51] where both hepatocytes and Kupffer cells respond by producing TNF and other cytokines [52]. Likewise, spleen, brain and bone marrow cells also produce cytokines following i.p. exposure to LPS [52-54]. Whether these cells are responding directly to the LPS or to the cascade of cytokines produced by the liver is not entirely clear. Pharmacokinetic experiments in mice indicate that TMP also spreads rapidly through the body following i.p. administration. Park, et al. [29] have shown that 4 hours after a single i.p. injection of TMP ( $2 \mathrm{mg})$ it can be readily detected in a variety of tissues and organs (liver, adipose tissue, brain, etc.) at $\mu \mathrm{M}$ concentrations comparable to those we utilized in vitro. TMP-mediated suppression of cytokine production in vivo may therefore be occurring at a variety of anatomical locations outside the peritoneal cavity and defining these sites will be the focus of future investigations.

It has been over two decades since TNF- $\alpha$ was identified as one of the major mediators of endotoxemia and cachexia [55]. Since then, TNF has been linked to a number of auto-immune and inflammatory disorders including; rheumatoid arthritis, inflammatory bowel disease, and psoriasis, to name a few (reviewed in [56]). Although expensive and difficult to administer, TNF- $\alpha$ blockers such as Infliximab, Etanercept, or Adalimumab have proven to be clinically effective for the management of these disorders [57]. The results of our experiments showed that TMP can reduce levels of TNF- $\alpha$ in vivo. While it is clear that many additional experiments remain to be performed, our results raise the possibility that TMP may be useful for treating inflammatory diseases that are mediated by TNF$\alpha$. Furthermore, the use of TMP may be advantageous over that of other TNF- $\alpha$ blockers because TMP also inhibits the production of other cytokines and inflammatory lipids. Elevated levels of MCP-1, for example, have been linked to psoriasis [58], while production of $\mathrm{PGE}_{2}$ contributes to rheumatoid arthritis [59]. In both of these diseases TMP might prove more effective than drugs that target only TNF- $\alpha$.

In summary, we have examined the ability of TMP to inhibit the secretion of cytokines, chemokines, and inflammatory lipids from activated macrophages. Our results show that TMP can inhibit production of both prostaglandins and several key inflammatory cytokines and chemokines. Therefore, TMP could potentially be used as a treatment for a number of different inflammatory disorders.

\section{Conclusion}

- TMP inhibited production of prostaglandins from LPSstimulated RAW 264.7 cells and from murine peritoneal macrophages.

- The ability of TMP to inhibit prostaglandin production was linked to effects on levels of COX-2 mRNA and protein and to inhibition of COX-2 enzymatic activity.

- TMP inhibited production of several key inflammatory cytokines and chemokines by RAW 264.7 cells and murine peritoneal macrophages.

- The ability of TMP to inhibit cytokine and chemokine production was correlated with effects on levels of cytokine and chemokine mRNA.

- TMP reduced levels of TNF- $\alpha$ and MCP-1 in the serum of mice challenged i.p. with a sublethal dosage of LPS.

- The ability of TMP to inhibit production of both protein and lipid mediators of inflammation suggests that it may have broad clinical application for the treatment of inflammatory and autoimmune disorders.

\section{Abbreviations}

TMP: terameprocol; LPS: lipopolysaccharide; TNF- $\alpha$ : tumor necrosis factor- $\alpha$; COX-2: cyclo-oxygenase-2; 
ELISA; enzyme-linked immunosorbent assay; q-rt-PCR: quantitative reverse transcriptase polymerase chain reaction; MCP-1: monocyte chemotactic protein-1; NDGA: nordihydroguaiaretic acid; HIV: human immunodeficiency virus; CPE: 20\% hydroxypropyl beta-cyclodextrin and 50\% polyethylene glycol 300; PMA: phorbol-12-myristate 13-acetate.

\section{Competing interests}

Erimos Pharmaceuticals produces TMP and would stand to benefit financially if TMP was used clinically to treat inflammation. None of the authors is paid by Erimos nor do they have stock or shares in the company. S.M.L. has a patent pending for the use TMP to treat inflammation associated with influenza infection but this application does not include claims relating to bacteria or bacterial products.

\section{Authors' contributions}

D.E., R.L.H. and C.A.C were responsible for investigating the effects of TMP on prostaglandin, cytokine and chemokine production. These individuals were responsible for all ELISA's and cytokine arrays.

C.E.C was responsible for defining the effects of TMP on COX-2 enzyme activity.

A.O.O. was responsible for investigating the effects of TMP on the expression of COX-2, cytokine, and chemokine mRNA.

F.S., I.T.D.P., and S.M.L. participated in design and coordination of the study, acquisition of funding, and drafting of the manuscript.

\section{Acknowledgements}

These experiments were funded by a grant from Erimos Pharmaceuticals, 930 Main Campus Dr., Suite 100, Raleigh, NC 27606.

\section{References}

I. Timmermann B: Practical uses of Larrea. In Creosote Bush Biology and Chemistry of Larrea in New World Deserts Edited by: Mabry T, Hunziker J, Difeo D. Dowden Hutchinson Ross Inc. USA; 1977:252-257.

2. Arteaga S, Andrade-Cetto A, Cardenas R: Larrea tridentata (Creosote bush), an abundant plant of Mexican and US-American deserts and its metabolite nordihydroguaiaretic acid. J Ethnopharmacol 2005, 98:231-239.

3. Katz M, Saibil F: Herbal hepatitis: subacute hepatic necrosis secondary to chaparral leaf. J Clin Gastroenterol I990, I 2:203-206.

4. Sheikh NM, Philen RM, Love LA: Chaparral-associated hepatotoxicity. Arch Intern Med 1997, I 57:913-919.

5. Bhattacherjee P, Boughton-Smith NK, Follenfant RL, Garland LG, Higgs GA, Hodson HF, Islip PJ, Jackson WP, Moncada S, Payne AN, Randall RW, Reynolds CH, Salmon JA, Tateson JE, Whittle BJR: The effects of a novel series of selective inhibitors of arachidonate 5-lipoxygenase on anaphylactic and inflammatory responses. Annals of the New York Academy of Sciences 1988, 524:307-320.

6. Salari H, Braquet $P$, Borgeat $P$ : Comparative effects of indomethacin, acetylenic acids, I5-HETE, nordihydroguaiaretic acid and BW755C on the metabolism of arachidonic acid in human leukocytes and platelets. Prostaglandins Leukot Med 1984, 13:53-60.

7. Bokoch GM, Reed PW: Effect of various lipoxygenase metabolites of arachidonic acid on degranulation of polymorphonuclear leukocytes. J Biol Chem 198I, 256:5317-5320.

8. Walenga RW, Showell HJ, Feinstein MB, Becker EL: Parallel inhibition of neutrophil arachidonic acid metabolism and lysosomal enzyme secretion by nordihydroguaiaretic acid. Life Sci 1980, 27:1047-1053.

9. Rossi F, Della Bianca V, Bellavite P: Inhibition of the respiratory burst and of phagocytosis by nordihydroguaiaretic acid in neutrophils. FEBS Lett I98I, I27:183-187.

10. Cheng JS, Jan CR: Effect of nordihydroguaiaretic acid on intracellular $\mathbf{C a}(2+)$ concentrations in hepatocytes. Toxicol In Vitro 2002, 1 6:485-490.

I I. Nakagawa T, Zhu H, Morishima N, Li E, Xu J, Yankner BA, Yuan J: Caspase- 12 mediates endoplasmic-reticulum-specific apoptosis and cytotoxicity by amyloid-beta. Nature 2000, 403:98-103.

12. Pardini RS, Heidker JC, Fletcher DC: Inhibition of mitochondrial electron transport by nor-dihydroguaiaretic acid (NDGA). Biochem Pharmacol 1970, 19:2695-2699.

13. Biswal SS, Datta K, Shaw SD, Feng X, Robertson JD, Kehrer JP: Glutathione oxidation and mitochondrial depolarization as mechanisms of nordihydroguaiaretic acid-induced apoptosis in lipoxygenase-deficient FL5.I2 cells. Toxicol Sci 2000, 53:77-83.

14. Yamaguchi T, Yamamoto A, Furuno A, Hatsuzawa K, Tani K, Himeno $M$, Tagaya M: Possible involvement of heterotrimeric $\mathbf{G}$ proteins in the organization of the Golgi apparatus. J Biol Chem 1997, 272:25260-25266.

15. Drecktrah D, de Figueiredo P, Mason RM, Brown WJ: Retrograde trafficking of both Golgi complex and TGN markers to the ER induced by nordihydroguaiaretic acid and cyclofenil diphenol. J Cell Sci 1998, I I I (Pt 7):95 I-965.

16. Ramoner R, Rieser C, Bartsch G, Thurnher M: Nordihydroguaiaretic acid blocks secretory and endocytic pathways in human dendritic cells. J Leukoc Biol 1998, 64:747-752.

17. Pavani M, Fones E, Oksenberg D, Garcia M, Hernandez C, Cordano G, Munoz S, Mancilla J, Guerrero A, Ferreira J: Inhibition of tumoral cell respiration and growth by nordihydroguaiaretic acid. Biochem Pharmacol 1994, 48: 1935-1942.

18. Suffys P, Beyaert R, Van Roy F, Fiers W: Reduced tumour necrosis factor-induced cytotoxicity by inhibitors of the arachidonic acid metabolism. Biochem Biophys Res Commun 1987, 149:735-743.

19. Hepburn A, Boeynaems JM, Fiers W, Dumont JE: Modulation of tumor necrosis factor-alpha cytotoxicity in L929 cells by bacterial toxins, hydrocortisone and inhibitors of arachidonic acid metabolism. Biochem Biophys Res Commun 1987, I49:8I 5-822.

20. Chang DJ, Ringold GM, Heller RA: Cell killing and induction of manganous superoxide dismutase by tumor necrosis factoralpha is mediated by lipoxygenase metabolites of arachidonic acid. Biochem Biophys Res Commun 1992, I 88:538-546.

21. Culver CA, Michalowski SM, Maia RC, Laster SM: The anti-apoptotic effects of nordihydroguaiaretic acid: inhibition of cPLA(2) activation during TNF-induced apoptosis arises from inhibition of calcium signaling. Life Sci 2005, 77:2457-2470.

22. Wagenknecht B, Gulbins E, Lang F, Dichgans J, Weller M: Lipoxygenase inhibitors block CD95 ligand-mediated apoptosis of human malignant glioma cells. FEBS Lett 1997, 409: I7-23.

23. Wagenknecht B, Schulz JB, Gulbins E, Weller M: Crm-A, bcl-2 and NDGA inhibit CD95L-induced apoptosis of malignant glioma cells at the level of caspase 8 processing. Cell Death Differ 1998, 5:894-900.

24. Gnabre JN, Brady JN, Clanton DJ, Ito Y, Dittmer J, Bates RB, Huang RC: Inhibition of human immunodeficiency virus type I transcription and replication by DNA sequence-selective plant lignans. Proc Natl Acad Sci USA I 995, 92: I I 239- I I 243.

25. Hwu JR, Tseng WN, Gnabre J, Giza P, Huang RC: Antiviral activities of methylated nordihydroguaiaretic acids. I. Synthesis, structure identification, and inhibition of tat-regulated HIV transactivation. I Med Chem 1998, 41:2994-3000.

26. Chen H, Teng L, Li JN, Park R, Mold DE, Gnabre J, Hwu JR, Tseng WN, Huang RC: Antiviral activities of methylated nordihydroguaiaretic acids. 2. Targeting herpes simplex virus replica- 
tion by the mutation insensitive transcription inhibitor tetraO-methyl-NDGA. J Med Chem 1998, 41:300I-3007.

27. Craigo J, Callahan M, Huang RCC, DeLucia AL: Inhibition of human papillomavirus type 16 gene expression by nordihydroguaiaretic acid plant lignan derivatives. Antiviral Research 2000, 47:19-28.

28. Heller JD, Kuo J, Wu TC, Kast WM, Huang RC: Tetra-O-methyl nordihydroguaiaretic acid induces $\mathbf{G} 2$ arrest in mammalian cells and exhibits tumoricidal activity in vivo. Cancer Res 200I, 61:5499-5504.

29. Park R, Chang CC, Liang YC, Chung Y, Henry RA, Lin E, Mold DE, Huang RC: Systemic treatment with tetra-O-methyl nordihydroguaiaretic acid suppresses the growth of human xenograft tumors. Clin Cancer Res 2005, I I:460 I-4609.

30. Lopez RA, Goodman AB, Rhodes M, Blomberg JA, Heller J: The anticancer activity of the transcription inhibitor terameprocol (meso-tetra-O-methyl nordihydroguaiaretic acid) formulated for systemic administration. Anticancer Drugs 2007, 18:933-939.

31. Raz A, Needleman P: Differential modification of cyclo-oxygenase and peroxidase activities of prostaglandin endoperoxidase synthase by proteolytic digestion and hydroperoxides. Biochem J 1990, 269:603-607.

32. Yun K-J, Kim J-Y, Kim J-B, Lee K-W, Jeong S-Y, Park H-J, Jung H-J, Cho Y-W, Yun K, Lee K-T: Inhibition of LPS-induced NO and PGE2 production by asiatic acid via NF-[kappa]B inactivation in RAW 264.7 macrophages: Possible involvement of the IKK and MAPK pathways. International Immunopharmacology 2008, 8:43|-44I.

33. Ahn KS, Noh EJ, Cha K-H, Kim YS, Lim SS, Shin KH, Jung SH: Inhibitory effects of Irigenin from the rhizomes of Belamcanda chinensis on nitric oxide and prostaglandin E2 production in murine macrophage RAW $\mathbf{2 6 4 . 7}$ cells. Life Sciences 2006, 78:2336-2342

34. Chen C-Y, Peng W-H, Tsai K-D, Hsu S-L: Luteolin suppresses inflammation-associated gene expression by blocking NF[kappa]B and AP-I activation pathway in mouse alveolar macrophages. Life Sciences 2007, 81:1602-1614.

35. Qi H-Y, Shelhamer JH: Toll-like Receptor 4 Signaling Regulates Cytosolic Phospholipase A2 Activation and Lipid Generation in Lipopolysaccharide-stimulated Macrophages. J Biol Chem 2005, 280:38969-38975

36. Kim J-Y, Park SJ, Yun K-J, Cho Y-W, Park H-J, Lee K-T: Isoliquiritigenin isolated from the roots of Glycyrrhiza uralensis inhibits LPS-induced iNOS and COX-2 expression via the attenuation of NF-[kappa]B in RAW 264.7 macrophages. European Journal of Pharmacology 2008, 584: $175-184$.

37. Wadleigh DJ, Reddy ST, Kopp E, Ghosh S, Herschman HR: Transcriptional Activation of the Cyclooxygenase-2 Gene in Endotoxin-treated RAW 264.7 Macrophages. J Biol Chem 2000, 275:6259-6266

38. Barnett J, Chow J, Ives D, Chiou M, Mackenzie R, Osen E, Nguyen B, Tsing S, Bach C, Freire : Purification, characterization and selective inhibition of human prostaglandin $\mathbf{G} / \mathbf{H}$ synthase I and 2 expressed in the baculovirus system. Biochim Biophys Acta 1994, 1209:130-139.

39. Matsuzaki J, Kuwamura M, Yamaji R, Inui H, Nakano Y: Inflammatory Responses to Lipopolysaccharide Are Suppressed in 40\% Energy-Restricted Mice. J Nutr 200I, I 3 I:2 I39-2 I 44.

40. Hoshino T, Nakaya T, Homan T, Tanaka K, Sugimoto Y, Araki W, Narita M, Narumiya S, Suzuki T, Mizushima T: Involvement of prostaglandin E2 in production of amyloid-beta peptides both in vitro and in vivo. J Biol Chem 2007, 282:32676-32688.

4I. Karouzakis E, Neidhart M, Gay RE, Gay S: Molecular and cellular basis of rheumatoid joint destruction. Immunol Lett 2006, 106:8-13.

42. Honda T, Segi-Nishida E, Miyachi Y, Narumiya S: Prostacyclin-IP signaling and prostaglandin E2-EP2/EP4 signaling both mediate joint inflammation in mouse collagen-induced arthritis. J Exp Med 2006, 203:325-335.

43. Humes JL, Sadowski S, Galavage M, Goldenberg M, Subers E, Kuehl FA, Bonney RJ: Pharmacological effects of non-steroidal antiinflammatory agents on prostaglandin and leukotriene synthesis in mouse peritoneal macrophages. Biochemical Pharmacology 1983, 32:2319-2322.
44. Chang J, Skowronek MD, Cherney ML, Lewis AJ: Differential effects of putative lipoxygenase inhibitors on arachidonic acid metabolism in cell-free and intact cell preparations. Inflammation 1984, 8: I43-I55.

45. Appleby SB, Ristimaki A, Neilson K, Narko K, Hla T: Structure of the human cyclo-oxygenase-2 gene. Biochem J 1994, 302(Pt 3):723-727.

46. Tsai EY, Falvo JV, Tsytsykova AV, Barczak AK, Reimold AM, Glimcher LH, Fenton MJ, Gordon DC, Dunn IF, Goldfeld AE: A lipopolysaccharide-specific enhancer complex involving Ets, Elk-I, Sp I, and CREB binding protein and p300 is recruited to the tumor necrosis factor alpha promoter in vivo. Mol Cell Biol 2000, 20:6084-6094.

47. Fessele S, Boehlk S, Mojaat A, Miyamoto NG, Werner T, Nelson EL, Schlondorff $D$, Nelson PJ: Molecular and in silico characterization of a promoter module and C/EBP element that mediate LPS-induced RANTES/CCL5 expression in monocytic cells. FASEB J 200I, I 5:577-579.

48. Turner M, Chantry D, Buchan G, Barrett K, Feldmann M: Regulation of expression of human IL-I alpha and IL-I beta genes. I Immunol 1989, I 43:3556-356I.

49. Itai T, Tanaka M, Nagata S: Processing of tumor necrosis factor by the membrane-bound TNF-alpha-converting enzyme, but not its truncated soluble form. Eur J Biochem 200I, 268:2074-2082.

50. Peschon JJ, Slack JL, Reddy P, Stocking KL, Sunnarborg SW, Lee DC, Russell WE, Castner BJ, Johnson RS, Fitzner JN, Boyce RW, Nelson N, Kozlosky CJ, Wolfson MF, Rauch CT, Cerretti DP, Paxton RJ, March C], Black RA: An Essential Role for Ectodomain Shedding in Mammalian Development. Science 1998, 282: $|28|-\mid 284$.

5I. Asari Y, Majima M, Sugimoto K, Katori M, Ohwada T: Release site of TNF alpha after intravenous and intraperitoneal injection of LPS from Escherichia coli in rats. Shock 1996, 5:208-212.

52. Scotte M, Hiron M, Masson S, Lyoumi S, Banine F, Teniere P, Lebreton $J P$, Daveau M: Differential expression of cytokine genes in monocytes, peritoneal macrophages and liver following endotoxin- or turpentine-induced inflammation in rat. Cytokine 1996, 8: II5-120.

53. Bultinck J, Brouckaert $P$, Cauwels $A$ : The in vivo contribution of hematopoietic cells to systemic TNF and IL-6 production during endotoxemia. Cytokine 2006, 36:160-166.

54. Blanque R, Meakin C, Millet S, Gardner CR: Selective enhancement of LPS-induced serum TNF-alpha production by carrageenan pretreatment in mice. Gen Pharmacol 1998, 31:301-306.

55. Beutler B, Milsark IW, Cerami AC: Passive immunization against cachectin/tumor necrosis factor protects mice from lethal effect of endotoxin. Science 1985, 229:869-87।.

56. Bradley JR: TNF-mediated inflammatory disease. J Pathol 2008, 214:149-160.

57. Wong M, Ziring D, Korin Y, Desai S, Kim S, Lin J, Gjertson D, Braun J, Reed E, Singh RR: TNF[alpha] blockade in human diseases: Mechanisms and future directions. Clinical Immunology 2008, 126:121-136.

58. Wang L, Yang L, Gao L, Gao TW, Li W, Liu YF: A functional promoter polymorphism in monocyte chemoattractant protein-I is associated with psoriasis. International Journal of Immunogenetics 2008, 35:45-49.

59. Martel-Pelletier J, Pelletier J-P, Fahmi H: Cyclooxygenase-2 and prostaglandins in articular tissues. Seminars in Arthritis and Rheumatism 2003, 33:155-167. 